OPEN ACCESS

Edited by:

Simone Brogi

University of Pisa, Italy

Reviewed by:

Cesare Indiveri

University of Calabria, Italy

Michael F. Wempe,

University of Colorado Denver,

United States

*Correspondence:

Lianwen Zheng

362683485@qq.com

Specialty section:

This article was submitted to Medicinal and Pharmaceutical

Chemistry,

a section of the journal

Frontiers in Chemistry

Received: 22 May 2020 Accepted: 17 September 2020 Published: 20 October 2020

Citation:

Zhang J, Xu Y, Li D, Fu L, Zhang X, Bao $Y$ and Zheng $L$ (2020) Review of the Correlation of LAT1 With Diseases:

Mechanism and Treatment.

Front. Chem. 8:564809.

doi: 10.3389/fchem.2020.564809

\section{Review of the Correlation of LAT1 With Diseases: Mechanism and Treatment}

\author{
Jingshun Zhang, Ying Xu, Dandan Li, Lulu Fu, Xueying Zhang, Yigang Bao and \\ Lianwen Zheng*
}

Reproductive Medical Center, Department of Obstetrics and Gynecology, The Second Hospital of Jilin University, Changchun, China

LAT1 is a member of the system $L$ transporter family. The main role of the LAT1 is to transport specific amino acids through cell membranes to provide nutrients to cells and participate in several metabolic pathways. It also contributes to the transport of hormones and some drugs, which are essential for the development and treatment of some diseases. In recent years, many studies have shown that LAT1 is related to cancer, obesity, diabetes, and other diseases. However, the specific mechanism underlying the influence of LAT1 on such conditions remains unclear. Through the increasing number of studies on LAT1, we have obtained a preliminary understanding on the function of LAT1 in diseases. These studies also provide a theoretical basis for finding treatments for LAT1-related diseases, such as cancer. This review summarizes the function and mechanism of LAT1 in different diseases and the treatment of LAT1-related diseases. It also provides support for the development of novel and reliable disease treatments.

Keywords: cancer, immune diseases, insulin resistance, mTOR, MYC, LAT1

\section{INTRODUCTION}

Although the main function of amino acids is participant in the production of protein, certain amino acids also play biological roles. For example, glutamine and glycine are necessary for nucleotide biosynthesis in essential cell proliferation processes. Serine has a key function as a one-carbon component that is indispensable to nucleotide synthesis and DNA methylation. Leucine and glutamine are vital signaling molecules and activators in several metabolic pathways (Bhutia et al., 2015). In mammals, the transmembrane transport of amino acids is regulated by multiple amino acid transporters (AAT), which are mainly located in the plasma membrane or intracellular compartments, such as Golgi apparatus, lysosomes, and mitochondria; these AAT promote the transmembrane exchange of amino acids or other substrates (Broer, 2002). Among AAT systems, the system L transporter family is one of the major plasma membrane transporter system. This family consists of four transporters: L-type AAT 1 (LAT1), coding by solute carrier family 7 member 5 (SLC7A5); L-type AAT 2 (LAT2), coding by solute carrier family 7 member 8 (SLC7A8); L-type AAT 3 (LAT3), coding by solute carrier family 43 member 1 (SLC43A1); L-type AAT 4 (LAT4), coding by solute carrier family 43 member 2 (SLC43A2) (del Amo et al., 2008). LAT1 is composed of 507 amino acids, contains 12 transmembrane regions, and has a molecular mass of 55,010 Da (Kanai et al., 1998; Mastroberardino et al., 1998). Its coding gene, SLC7A5, is located at 16q24.2 and contains 39,477 nucleotides and 10 exons. SLC7A5 belongs to the SLC7 family included in the larger APC (Amino acid-polyamine-organocation) superfamily. The SLC7 family consists of 15 
members, two of which are pseudogenes. The 13 encoded proteins are classified in two subgroups: the cationic amino acid transporters and the light subunits (LATs) of the heterodimeric amino acid transporters (Scalise et al., 2018). LAT1 usually combines with $4 \mathrm{~F} 2$ cell-surface antigen heavy chain (4F2hc; coding by solute carrier family 3 member 2, SLC3A2), a type II membrane glycoprotein that forms a heteromeric AAT complex via disulfide bonding; this complex is important for the stability of LAT1 and for localization to the plasma membrane (Yanagida et al., 2001; Verrey et al., 2004).

As a member of the system $L$ transporter family, the main function of the LAT1 protein is to help specific amino acids pass through the cell membrane to provide nutrients to cells and participate in some metabolic pathways. The effect of LAT1 on human metabolism depends on its capability to identify specific amino acids and hormones as major physiological substrates and several drugs as non-physiological substrates (Scalise et al., 2018). LAT1 is a sodium-independent transporter and mainly responsible for the transport of branched-chain amino acids (BCAAs; e.g., valine, isoleucine, and leucine) and bulky amino acids (e.g., phenylalanine, tyrosine, tryptophane, asparagine, histidine and methionine). It is independent of any transmembrane ion gradient and is a compulsory exchanger, indicating that the flow of an amino acid into cell through LAT1 is forced to couple with the outflow of another amino acid (Bhutia et al., 2015). LAT1 also contribute to the transport of the hormones like T3, T4 and drugs, such as the dopamine precursor L-DOPA, melphalan, methyldopa, and gabapentin, which are essential for the development and treatment of some organs, particularly the brain, as well as the metabolic and pharmaceutical control of all tissues throughout life (Cornford et al., 1992; Friesema et al., 2001; Uchino et al., 2002; del Amo et al., 2008). Previous research showed that the expression of the LAT1 gene varies in accordance with tissue and cell type. LAT1 is highly expressed in mouse and human brains, testes, ovaries, pancreatic islets, and placentas but expressed at low levels in the lungs, hearts, and liver. It may provide nutrient substances for the normal function of these organs and cells. Although systemic capillary endothelial cells do not express LAT1, LAT1 is highly positively expressed in capillaries corresponding to the blood-brain barrier (BBB), blood follicles, and blood-retinal barrier (BRB) (Yanagida et al., 2001; Asano et al., 2007). Systemic homozygous LAT1 gene deletion can cause embryonic lethality among LAT1-knockdown embryos without apparent defects at day 8.5 of embryonic development. Soon after further embryonic development, the heads of the mutant embryos shrink and their trunks and tails shorten. These effects become serious at day 10.5 of embryonic development. Finally, no living LAT1-knockdown embryos are found at day 11.5 of embryonic development (Ohgaki et al., 2017). Mice lacking the domain required for interaction with LAT1 in SLC3A2 also fail to survive in the early stage of embryonic development (Tsumura et al., 2003), an outcome that can be attributed to the harmful influence of the lack of LAT1 transport function during mouse embryonic development after implantation (Sato et al., 2011). These phenomena explain the importance of the proper expression of LAT1 for embryonic development.

\section{LAT1-RELATED DISEASES}

Cell growth and proliferation rely heavily on the acquisition of exogenous amino acids, which are mainly used in proteins, nucleic acids, lipids, and adenosine triphosphate (ATP) biosynthesis (Wang and Holst, 2015). Therefore, AAT malfunction impairs the whole-body dynamic balance and causes a variety of human diseases, including cancer, insulin resistance, diabetes, immune diseases, inflammation, and so on. Although the specific mechanism of influence is not clear, it can also provide us with some new directions for the treatment of these diseases.

\section{LAT1 and Cancer}

The proliferation of cancer cells is highly dependent on nutrients, in particular, some essential amino acids (EAAs) are essential. Their uptake of amino acids through the cell membrane is strictly controlled by membrane transporters. These transporters are usually increased in cancer cells relative to in normal cells to satisfy the substantial intake of amino acids during tumor progression (Wang and Holst, 2015). Numerous studies have suggested that LAT1 expression in cancerous tissues is higher than that in normal tissues and LAT1 expression is correlated with the growth and proliferation of cancer cells. These data are collected across a large number of cancers, showing in the Table 1. All previous studies indicated the importance of LAT1 in supporting the rapid growth and proliferation of cancers (Kim et al., 2004; Kaira et al., 2008a, 2009a, 2011a, 2012, 2013a; Ichinoe et al., 2011; Toyoda et al., 2014; Namikawa et al., 2015; Honjo et al., 2016; Hayase et al., 2017; El Ansari et al., 2018). For example, LAT1 expression in 53 ovarian cancer tissues was detected and compared with those in five normal ovarian tissues and five benign ovarian tumor tissues. LAT1 is obviously increased in various human epithelial ovarian cancers and ovarian cancer cell lines and is mainly located in the plasma membrane of ovarian cancer cells. LAT1 expressions in the ovarian cancer cell lines SKOV3, IGROV1, OVCAR3, and A2780 and the normal ovarian epithelial cell line ISOE397 are $22,29,24,11$, and 10 times higher than that in the normal ovary. LAT1 levels in ovariectomized tissues are also distinctly upregulated compared with those in benign ovarian tumors. The increased level of LAT1 may be associated with the proliferation and invasion capability of ovarian cancer cells (Kaji et al., 2010). Moreover, LAT1 expression is significantly higher in breast cancer than in normal breast tissue and more obvious in advanced breast cancer, indicating that LAT1 can act as a potential therapeutic target (El Ansari et al., 2018). By contrast, the inhibition or knockout of LAT1 expression by inhibitors and small interfering RNA (siRNA) can reduce the migration and invasion of cholangiocarcinoma cells in vitro, suggesting that the transport function of LAT1 is crucial for providing necessary nutrition to metastatic cancer cells (Janpipatkul et al., 2014).

LAT1 level in tumors was recently proven to be an independent prognostic indicator (Nakanishi et al., 2006; Imai et al., 2009; Kaira et al., 2009b; Sakata et al., 2009; Ichinoe et al., 2011). In mice, the tumors produced by strongly LAT1-positive cells are larger than those produced by cells expressing low 
TABLE 1 | Expression of L-type amino acid transporter 1 (LAT1) in different tumor types.

\begin{tabular}{|c|c|c|c|}
\hline Cancer type & Expression & References & Meaning \\
\hline Tongue cancer & $\uparrow$ & $\begin{array}{l}\text { Kaira et al., 2008b; } \\
\text { Toyoda et al., } 2014\end{array}$ & $\begin{array}{l}\text { An independent } \\
\text { prognostic factor }\end{array}$ \\
\hline $\begin{array}{l}\text { Oral squamous cell } \\
\text { carcinoma }\end{array}$ & $\uparrow$ & Kim et al., 2004 & $\begin{array}{l}\text { A more specific } \\
\text { indicator of tumor } \\
\text { progression }\end{array}$ \\
\hline $\begin{array}{l}\text { Esophageal } \\
\text { squamous cell } \\
\text { carcinoma }\end{array}$ & $\uparrow$ & $\begin{array}{l}\text { Honjo et al., 2016; } \\
\text { Hashimoto et al., } 2017\end{array}$ & $\begin{array}{l}\text { The prognostic } \\
\text { biomarker and } \\
\text { therapeutic target }\end{array}$ \\
\hline $\begin{array}{l}\text { Thymic epithelial } \\
\text { tumor }\end{array}$ & $(+)$ & Kaira et al., 2009a & $\begin{array}{l}\text { The } \\
\text { immunohistochemical } \\
\text { marker for } \\
\text { carcinomas }\end{array}$ \\
\hline Breast cancer & $\uparrow$ & $\begin{array}{l}\text { Kaira et al., 2008b; El } \\
\text { Ansari et al., } 2018\end{array}$ & $\begin{array}{l}\text { An independent risk } \\
\text { factor }\end{array}$ \\
\hline $\begin{array}{l}\text { Malignant pleural } \\
\text { mesothelioma }\end{array}$ & $\uparrow$ & Kaira et al., 2011a & $\begin{array}{l}\text { Associated with poor } \\
\text { outcome }\end{array}$ \\
\hline Lung tumor & $\uparrow$ & $\begin{array}{l}\text { Kaira et al., 2008a; } \\
\text { Rosilio et al., } 2015\end{array}$ & $\begin{array}{l}\text { Associated with } \\
\text { lymph node } \\
\text { metastasis and poor } \\
\text { outcome }\end{array}$ \\
\hline Gastric carcinoma & $\uparrow$ & Ichinoe et al., 2011 & $\begin{array}{l}\text { An independent } \\
\text { prognostic factor }\end{array}$ \\
\hline $\begin{array}{l}\text { Hepatocellular } \\
\text { carcinoma }\end{array}$ & $\uparrow$ & Namikawa et al., 2015 & $\begin{array}{l}\text { An independent and } \\
\text { significant prognostic } \\
\text { factor }\end{array}$ \\
\hline Pancreatic cancer & $\uparrow$ & Kaira et al., 2012 & $\begin{array}{l}\text { A significant } \\
\text { prognostic factor }\end{array}$ \\
\hline Biliary tract cancer & $\uparrow$ & $\begin{array}{l}\text { Kaira et al., 2013a; } \\
\text { Yanagisawa et al., 2014; } \\
\text { Yothaisong et al., } 2017\end{array}$ & $\begin{array}{l}\text { A significant } \\
\text { independent } \\
\text { predictor }\end{array}$ \\
\hline Colorectal cancer & $\uparrow$ & $\begin{array}{l}\text { Kaira et al., 2008b; } \\
\text { Hayase et al., } 2017\end{array}$ & $\begin{array}{l}\text { Associated with } \\
\text { cancer cell } \\
\text { proliferation via the } \\
\text { mTOR pathway }\end{array}$ \\
\hline Bladder tumors & $\uparrow$ & Xie et al., 2013 & $\begin{array}{l}\text { An independent } \\
\text { prognostic factor }\end{array}$ \\
\hline Prostate cancer & $\uparrow$ & Wang et al., 2011 & $\begin{array}{l}\text { Expression when } \\
\text { hormone ablation and } \\
\text { in metastatic lesions }\end{array}$ \\
\hline $\begin{array}{l}\text { Clear cell renal cell } \\
\text { carcinoma }\end{array}$ & $\uparrow$ & Betsunoh et al., 2013 & $\begin{array}{l}\text { Related to the } \\
\text { invasive and } \\
\text { progressive potential }\end{array}$ \\
\hline $\begin{array}{l}\text { Malignant glioma } \\
\text { cells }\end{array}$ & $\uparrow$ & $\begin{array}{l}\text { Nawashiro et al., 2006; } \\
\text { Kobayashi et al., 2008; } \\
\text { Haining et al., } 2012\end{array}$ & $\begin{array}{l}\text { The molecular target } \\
\text { in glioma therapy }\end{array}$ \\
\hline $\begin{array}{l}\text { Endometrial } \\
\text { carcinoma }\end{array}$ & $\uparrow$ & Marshall et al., 2016 & $\begin{array}{l}\text { An effective } \\
\text { therapeutic strategy }\end{array}$ \\
\hline $\begin{array}{l}\text { Ovarian clear cell } \\
\text { carcinoma }\end{array}$ & $\uparrow$ & Sato et al., 2019 & $\begin{array}{l}\text { Associated with poor } \\
\text { prognosis and } \\
\text { chemoresistance }\end{array}$ \\
\hline $\begin{array}{l}\text { Cutaneous } \\
\text { melanoma }\end{array}$ & $\uparrow$ & Shimizu et al., 2015 & $\begin{array}{l}\text { An independent } \\
\text { prognostic factor }\end{array}$ \\
\hline Bone tumors & $\uparrow$ & Koshi et al., 2015 & \\
\hline Soft tissue tumors & $\uparrow$ & $\begin{array}{l}\text { Kaira et al., 2008b; } \\
\text { Koshi et al., } 2015\end{array}$ & \\
\hline $\begin{array}{l}\text { Lymphoblastic } \\
\text { leukemia }\end{array}$ & $\uparrow$ & Rosilio et al., 2015 & $\begin{array}{l}\text { An efficient } \\
\text { broad-spectrum } \\
\text { adjuvant approach }\end{array}$ \\
\hline
\end{tabular}

$\uparrow$ means increased expression; (+) means positive expression.
LAT1 levels (Salisbury and Arthur, 2018). The high expression of LAT1 in ovarian cancer has been verified to be associated with poor prognosis. The results of multivariate analysis showed that high LAT1 levels can serve as an independent variable that is suggestive of poor prognosis and FIGO stage III/IV (vs. I/II) in patients with ovarian carcinoma (Sato et al., 2019). The Kaplan-Meier analysis of patients with adenoid cystic carcinoma revealed that the total survival time of patients with low LAT1 levels is significantly longer than that of patients with high LAT1 levels, signifying that LAT1 is a predictive indicator of the poor prognosis of patients with adenoid cystic carcinoma (Kaira et al., 2013b). T-cell acute lymphoblastic leukemia (T-ALL) is a highly invasive disease that involves thymocyte transformation (Aifantis et al., 2008). The survival rate of mice with LAT1silenced T-ALL tumors is better than that of mice with LAT1expressing T-ALL tumors (Grzes et al., 2017). The relationship of the level of LAT1 with the malignant degree and prognosis of lung neuroendocrine tumors was investigated. The study included 21 cases of large cell neuroendocrine carcinomas (LCNEC), 13 cases of small-cell lung cancers, 5 cases of atypical carcinoids, and 10 cases of typical carcinoids. The results indicated that the level of LAT1 in LCNEC is positively correlated with lymph node metastasis and poor patient prognosis, and the expression of LAT1 increases as the malignancy of neuroendocrine tumors increases. Therefore, LAT1 is closely related to lymph node metastasis and poor prognosis in patients with lung neuroendocrine tumors (Kaira et al., 2008a). The level of LAT1 is also an important prognostic indicator in patients with pancreatic cancer. Among 97 patients with pancreatic ductal adenocarcinoma, $\sim 53 \%$ have an upregulated level of LAT1, which is positively related to cancer cell proliferation, tumor angiogenesis, and disease progression (Kaira et al., 2012; Yanagisawa et al., 2012). Endometrial cancer is a major gynecological cancer in developed countries, and endometrial adenocarcinoma is its most common subtype, representing $\sim 80 \%$ of all cases (Jemal et al., 2011). A Western diet is believed to be a factor that influences anomalous cell proliferation by providing an excess supply of animal proteins, especially BCAAs, such as leucine (O'Connell, 2013). LAT1 in serotypes and endometrioid endometrial adenocarcinomas is significantly upregulated relative to that in the normal endometrium. Patients with endometrial adenocarcinoma with the highest level of LAT1 have the lowest disease-free survival rate. LAT1 gene knockout significantly reduces leucine uptake by $51-58 \%$ and reduces cell growth in endometrial carcinoma cell lines. These results indicated that LAT1 is extremely essential to the regulation of leucine uptake and cell growth in endometrial cancer cells and the progression of endometrial carcinoma (Marshall et al., 2016). All the above results confirmed that LAT1 is significantly correlated with the invasiveness and prognosis of various cancers. Thus, LAT1 is a potential index for predicting the prognosis of patients with cancer.

LAT1 has also been shown to be associated with chemotherapy resistance. An analysis of the chemotherapy response of ovarian cancer revealed that several genes, including LAT1, can be critical factors leading to chemoresistance. LAT1 is a solute carrier protein that may regulate the absorption of drugs by cancer cells, thus regulating chemotherapy response. Therefore, LAT1 may 
be a novel target for improving the effect of chemotherapy on ovarian cancer (Cheng et al., 2010). LAT1 is also an indicator antibody in the endocrine therapy of breast cancer, where its high level may serve as a recurrence factor of estrogen-receptor positive breast cancer (Bartlett et al., 2010). LAT1 have a key role in the diverse periods of prostate cancer development. LAT1 is mainly expressed in the androgen-insensitive prostate cancer cell line PC-3. LAT1 levels is low in normal or benign prostate tumor tissues. With the transformation of hormone-sensitive prostate cancer to hormone-refractory prostate cancer, such as in castraton-resistant metastatic cancer tissue, the level of LAT1 is significantly upregulated. These results suggest that the increased level of LAT1 contributes to hormone-refractory prostate cancer and LAT1 may be a feasible target for the treatment of advanced prostate cancer (Wang et al., 2011, 2013). With the increasing number of cancer treatment methods, such as surgery, chemotherapy, radiotherapy, and other combined applications, the cure and survival rate of patients with cancer have increased significantly. However, chemoresistance has become a difficult problem encountered in current cancer treatment processes. Targeting LAT1 to improve the chemoresistance of patients with cancer may be another great progress in medical treatment.

\section{LAT1 and Insulin Resistance}

Amino acids are increasingly considered as the regulators of nutrient processing (Lynch and Adams, 2014). For example, they regulate blood glucose levels through their interaction with insulin signals. The membrane transporters of amino acids were recently shown to be a key part of this regulatory process. Amino acids that are regulated by transporters can promote insulin secretion and regulate insulin signals in different tissues. Glucose also regulates the expression of LAT1. In patients with diabetes, an increase in blood glucose levels will reduce LAT1 expression and, subsequently, muscle reduction (muscular atrophy) (Yamamoto et al., 2017). By contrast, glucose deficiency upregulates LAT1 expression in the retina. The inner BRB is a delicate, compact junction of retinal capillary endothelial cells; it protects nerves and the retina from the effects of circulating blood and nourishes two-thirds of the cells in the retina (Hosoya and Tomi, 2005; Hosoya and Tachikawa, 2009). LAT1 is expressed in the internal BRB and provides EAAs to the neuroretina and retinal endothelial cells (Tomi et al., 2005). It is the major transporter of BCAAs in many non-epithelial cells and is directly involved in insulin secretion through leucine accumulation in the cytoplasm (Yoon, 2016). LAT1 is highly expressed in islets. The siRNA knockout of LAT1 in dispersed islet cells leads to a significant reduction in leucine-stimulated S6K1 phosphorylation, leucine-mediated insulin production, and islet cell proliferation. These effects indicate that LAT1 is necessary for the action of mammalian target of rapamycin complex 1 (mTORC1) and the mediation of islet $\beta$-cell signal and function; LAT1 may also be a new drug target for the therapy and prevention of type 2 diabetes (T2D) (Cheng et al., 2016). The realization that BCAAs, like leucine, is necessary for signal activation of the mTORC1 signal, a downstream molecule of insulin, has prompted many recent studies on the use of dietary leucine as an auxiliary therapy for obesity-associated insulin resistance. Doubling dietary leucine content can reverse numerous metabolite abnormalities and significantly improve glucose tolerance and the insulin pathway without influencing food intake or weight gain. Increasing dietary leucine greatly relieves hepatic steatosis and inflammation in adipose tissue. The above studies deduced that moderate changes in LAT1 levels can alter multiple metabolic pathways and insulin resistance (Macotela et al., 2011; Adeva et al., 2012). Insulin resistance is a common metabolic disorder, and its etiology is complex and not completely clear. If the role of LAT1 in the occurrence and development of insulin resistance is identified, then obesity, $\mathrm{T} 2 \mathrm{D}$, and other diseases associated with insulin resistance may be treated by modifying LAT1 expression or providing LAT1 substrates, such as leucine.

\section{LAT1 and Immune Diseases}

The LATs, including LAT1, are potential immunosuppressive targets; For example, the high-affinity inhibitor of LATs, brasilicardin $\mathrm{A}$ is an effective immunosuppressant (Usui et al., 2006). T lymphocytes mediate adaptive immune reaction to antigens by producing and differentiating effectors. Therefore, activated $\mathrm{T}$ cells must be capable of upregulating their metabolism levels in time to meet the demands of normal reactions. In T cells, the regulation of LAT1 through the T-cell antigen receptor (TCR) is crucial for the effective functioning of immune response and the reprogramming of T-cell metabolism. For example, T-cell activation is necessary to upregulate the corresponding amino acid intake of cells through LAT1 to increase protein synthesis. Moreover, these amino acids are not only used to synthesize proteins (Wang and Green, 2012) but are also important for the CD8 cytotoxic T-cell (CTL) reaction. The response function of LAT1-null $\mathrm{CD} 8^{+} \mathrm{T}$ cells to the cytotoxic effects of homologous antigens may be severely deficient (Sinclair et al., 2013). LAT1-specific knockout $\mathrm{CD}^{+} \mathrm{T}$ cells can inhibit the inflammatory reaction induced by imiquimod. In the inflammatory model induced by imiquimod, the absence or inhibition of LAT1 will block the expansion of IL-17-secreting $\mathrm{T}$ cells and $\mathrm{CD}^{+} \mathrm{T}$ cells as well as inhibit the production of the inflammatory cytokines IL-1 $\beta$, IL-17, and IL-23. By contrast, IL23 and IL-1 $\beta$ can stimulate the upregulation of LAT1 expression and promote the immune response. These results indicate that targeting LAT1 may be a potential immunosuppressive strategy to control skin inflammation induced by the IL-23/IL-1 $\beta /$ IL-17 axis (Cibrian et al., 2020). Histidine, a high-affinity substrate of LAT1, lays a foundation for explaining the following phenomena. The upregulated expression of LAT1 will increase histidine, obviously decrease the activation of nuclear factor-kappa B (NF$\kappa \mathrm{B})$ and the stimulation of TNF- $\alpha$, and control the level of Eselectin and the generation of IL- 6 in human coronary arterial endothelial cells (HCAECs). The activation of NF- $\kappa \mathrm{B}$ regulates the generation of various cytokines and the level of adhesion molecules involved in inflammatory diseases. The above study shows that in some cases, the increased expression of LAT1 also affects immunosuppression by affecting the histidine and NF-kB pathways in HCAECs (Hasegawa et al., 2012). LAT1 expression is reduced in an in vitro pancreatitis model and is associated with the role of LAT1 in acinar cells. Acinar cells accumulate 
amino acids through LAT1 and form a significant concentration gradient to synthesize digestive enzymes. However, LAT1 was not reduced in the in vivo pancreatitis model at RNA level and neither at protein level. They thought that LAT1 may be expressed in another cell population of which expression increases and masks the loss in the acinar cells in the in vivo model. Pancreatitis is a degenerative self-digestion process that is accompanied by the damage of exocrine acinar tissue and then by a regeneration process. Specific amino acid support has been confirmed to be beneficial to the cure of severe pancreatitis. Therefore, the reduction in amino acid levels caused by the decreased expression of LAT1 may be a reason for the aggravation of pancreatitis (Rooman et al., 2013). Because LAT1 provides cells with the most basic substance, amino acids. Whether in the process of anti-inflammation or in the occurrence and progress of inflammation, it may play an important role and maintain a dynamic balance. When the body is functioning normally, LAT1 may play an anti-inflammatory function. If the body is decompensated, LAT1 may accelerate the development of the disease and promote inflammation. At present, studies on the role of LAT1 in immune-related diseases remain scarce. However, LAT1 has been confirmed to be involved in immune and inflammatory responses. Thus, LAT1 may be used to explore a novel method for treating immune and inflammatory diseases.

\section{LAT1 and Neurological Disorders}

LAT1 is a vital protein for organ growth and development because it is involved in the transport of eight of the nine EAAs to corresponding tissues (Hafliger and Charles, 2019). LAT1 is strongly expressed in the luminal and abluminal membranes of brain microvessel endothelial cells in all brain regions, including the cerebral cortex, cerebellum, hippocampus, gray matter, and white matter. It plays a key role in amino acid, hormone, and drug transfer across the BBB (Duelli et al., 2000). Reduced levels of LAT1 in the BBB are associated with the incidence and progression of Parkinson's disease (Ohtsuki et al., 2010). LAT1 is responsible for the transport of the dopamine precursor L-DOPA across the BBB. Therefore, reduced LAT1 expression leads to a decrease in L-DOPA distribution, which results in a corresponding reduction in dopamine production; this decrement is currently recognized as the cause of Parkinson's disease (Kageyama et al., 2000). Phenylketonuria (PKU) is caused by inherited phenylalanine hydroxylase $(\mathrm{PAH})$ deficiency and is characterized by elevated blood levels of phenylalanine. The LAT1 is responsible for phenylalanine transport across the BBB. As phenylalanine excess in the brain leads to mental retardation in untreated patients with PKU, they deduced mutations of the LAT1 gene may be responsible for this situation (BikMultanowski and Pietrzyk, 2006). However, some scholars have analyzed the gene sequence variants in PKU patients. None of the identified variants changed the amino acid residues, nor did they lead to any formation of new splice sites, according to the consensus sequence for splice sites (Moller et al., 2005). Therefore, the exactly relationship between LAT1 gene mutations and PKU needs further study. The function of LAT1 in BBB can also be illustrated through the transport of tryptophan. Tryptophan is another EAAs and is a precursor of serotonin, melatonin, and vitamin B3, all of which are essential for the normal development of the nervous system (Walderhaug et al., 2002). Abnormal tryptophan levels affect behavioral and cognitive processes. A significant correlation exists between the anxiety index and tryptophan, as well as between $\mathrm{T}$ maze error, a recognized spatial working memory assessment tool, and LAT1. This relationship suggests that the decrease in LAT1 expression leads to a reduction in tryptophan transport through the BBB and affects neurological development (Asor et al., 2015). The change of LAT1 function in the BBB was also recently considered to be the molecular determinant of the autism spectrum disorder (ASD) (Al-Otaish et al., 2018; Smith et al., 2019). In a study, ninety-seven patients with ASD were screened by Sanger sequencing the genes, including LAT1. It was detected nine pathogenic variants in 11 of 97 patients (11.3\%), and three among LAT1. Metabolic assays illustrated that such abnormalities affect the utilization of certain amino acids, particularly tryptophan and other LNAAs, with potential consequences on their transport across the BBB and their availability during brain development. Therefore, they concluded abnormalities in the LAT1 and are likely associated with an increased risk of developing ASD (Smith et al., 2019). The study by Tărlungeanu et al. reported two homozygous mutations (p. Ala246Val and p. Pro375Leu) in the LAT1 gene in patients with ASD and motor delay, and estimated the impact of these mutations on amino acid transport across BBB in a mouse model. The knockout of LAT1 in BBB endothelial cells in mice will result in atypical amino acid profiles, abnormal mRNA translation, and obvious neurological defects. The levels of leucine and isoleucine were reduced and the levels of histidine were increased significantly, and these abnormalities were rescued by intracerebroventricular injection of BCAAs. In addition, patients with deleterious homozygous mutations of the LAT1 gene in their BBBs will show some symptoms of autism characteristics and motor delay (Zheng et al., 2009; Tarlungeanu et al., 2016). These findings suggest potential dysfunction of LAT1 in individuals with ASD. Therefore, LAT1 can be used not only for amino acid delivery but also for the targeted treatment of brain and nervous system diseases.

It is a great challenge for the treatment of central nervous system (CNS) diseases, especially for neurodegenerative diseases, to deliver therapeutic drugs to brain lesions. In order to overcome this problem, various methods of drug delivery in the brain have been designed (Dong, 2018). The development of prodrugs similar with endogenous substrates of influx transporters, which are selectively expressed on the BBB and brain parenchyma cell membrane is a promising way of drug administration. After the prodrug mediated by transporter passes through the BBB and cell membrane barrier, the patent drug will be released at the target site of its brain parenchyma cells, so that the drug has a higher therapeutic concentration in the focus and improves the therapeutic effect (Puris et al., 2019a). Therefore, some scholars have developed LAT1-targeting prodrugs, which can significantly improve the cellular and brain uptake of several parent drugs, such as anti-inflammatory agent ketoprofen (Gynther et al., 2008), anti-epileptic drug valproic acid (Gynther et al., 2016a), anti-parkinsonian prodrug of dopamine(Thiele et al., 2018), investigational immunosuppressive perforin inhibitors (Gynther 
et al., 2016b), and natural phenolic antioxidant ferulic acid (Puris et al., 2019b). In a recent study, six LAT1-utilizing prodrugs were studied. All prodrugs were accumulated into the brain cells comparably and most cases even more effectively than their parent drugs. And in order to confirm that the cellular uptake these drugs were mediated via LAT1, the uptake of prodrugs was studied in the absence and the presence of LAT1-inhibitor (Huttunen et al., 2016). The result suggested that LAT1 -inhibitor has been able to reduce the uptake of the prodrugs in human breast cancer (MCF-7) or retinal pigmented epithelial (ARPE19) cells by $65-93 \%$ (Puris et al., 2017, 2019b). Therefore, they concluded LAT1 can be utilized to increase the cellular uptake of drugs into the brain parenchymal cells by using a LAT1-prodrug approach (Huttunen et al., 2019). In another study suggested the LAT1-utilizing prodrug of ketoprofen achieved a higher extent of intracellular distribution from brain extracellular fluid (ECF) than the parent drug, ketoprofen. Meanwhile, the LAT1utilizing prodrug of ketoprofen had no effect on the protein expression of LAT1 and CD98 subunit of the transporter in crude membranes of mouse and rat brain slices (Puris et al., 2019a). This study suggests that the LAT1-utilizing prodrug method may be a promising way to deliver drugs to the inner septum of brain parenchyma cells. In short, the above researches highlight the importance of the role of LAT1 in intra-brain targeted drug delivery which can lead to improved efficacy and safety of neuroprotective drugs within the brain.

\section{LAT1 and Other Diseases}

In placentas, chorionic trophoblast cells differentiate into syncytiotrophoblast cells through cell fusion and maternal-fetal separate circulation. LAT1 is expressed on the maternal and fetal surfaces of the syncytiotrophoblast and plays a key part in the exchange of nutrient substances across the placental barrier (Ohgaki et al., 2017). LAT1 expression has been suggested to reduce in intrauterine growth restriction (IUGR), indicating that maternal nutrition to the fetus through the placental barrier is inadequate. Fetuses born with IUGR also have a significantly increased risk of suffering cardiovascular and metabolic diseases when they grow up (Pantham et al., 2016). Maternal obesity may be responsible for the increased expression of LAT1 in the placenta and for subsequent fetal overgrowth. Hence, the importance of normal LAT1 expression in placentas is further emphasized (Rosario et al., 2015). Given that the participation of LAT1 in many other diseases has not been found so far, the role of LAT1 in diseases should receive additional attention in the future.

\section{MECHANISMS OF LAT1 IN DISEASES}

As we summarized before, LAT1 is involved in the occurrence and development of many diseases, but how does it work? At present, there have been several studies on the mechanism of LAT1, although it is not clear, but it also provides us with some ideas to understand the occurrence of these diseases from another point of view.

\section{LAT1 and Mammalian Target of Rapamycin}

LAT1 is located on cell surfaces and interacts with the intracellular nutrient signaling pathways (e.g., mTORC1 pathway) that regulate cell metabolism (Hundal and Taylor, 2009). Mammalian target of rapamycin (mTOR) is a member of the phosphoinositide 3 kinase-related kinase family, which has the catalytic activity of protein serine threonine kinase. mTOR is mainly present in two kinds of complexes in cells: mTORC1 and mTORC2. mTORC1 consists of mTOR complexed with mLST8, RAPTOR, PRAS40, and DEPTOR; it activates S6 kinase and inhibits the eIF-4E binding protein (Hara et al., 1997). This complex harmonizes signals from pressure, energy state, and oxygen supply to coordinate cell autophagy, growth, and protein synthesis. mTORC2 is composed of mTOR complexed with mLST8, RICTOR, and mSin1; this complex is mainly regulated by growth factors and affects cell growth and metabolism (Sarbassov et al., 2004; Jacinto et al., 2006; Sancak et al., 2010; Arnsburg and Kirstein-Miles, 2014). In an environment rich in amino acids, mTOR can stimulate and regulate protein synthesis while inhibiting autophagy. If extracellular amino acids are restricted, then autophagy will be activated to recycle other intracellular components as substitute sources of amino acids (Nicklin et al., 2009; Saxton and Sabatini, 2017). LAT1 sometimes enters lysosomal membranes through lysosomal-associated transmembrane protein $4 \mathrm{~b}$ and regulates leucine exchange into the lysosome (Milkereit et al., 2015). After entering the lysosome, leucine can regulate the activation of lysosomal membrane $\mathrm{H}+\mathrm{ATPase}$ (V-ATPase), which is an important component of the mTORC1 activator complex on the lysosomal surface, thereby promoting the activation of mTORC1 (Zoncu et al., 2011). Meanwhile, LAT1 expression is adjusted by transcription factor 4 (ATF4) by signaling in an mTORC1-dependent manner. Cell nutrition insufficiency caused by amino acid deficiency activates ATF4, which guides aminoacid transport into cells. Elevated ATF4 levels upregulate LAT1, resulting in an increased uptake of isoleucine or leucine and therefore activating $\mathrm{mTORC} 1$ and inhibiting autophagy. Recent studies have shown that the knockout of LAT1 or ATF4 can block amino acid uptake, prevent mTORC1 activation, and enhance autophagy (Chen et al., 2014). mTORC1 mainly regulates cell metabolism and protein synthesis. The abnormal activation of mTORC1 is related to various diseases. First, the mTORC1 signal accelerates tumor development by influencing various metabolic pathways to promote the growth, proliferation, and anti-apoptosis of cancer cells. Recent studies have suggested that human prostate cancer cell lines can upregulate the absorption of amino acids through LAT1, thereby promoting mTORC1 signal transduction and cell growth (Wang et al., 2011). The pharmacologic inhibition or knockout of LAT1 can inhibit the growth and mTOR signaling pathways of various tumor cell lines, such as human colon adenocarcinoma cells (LS174T and HT29), lung cancer cells (A549 and H1975), and renal carcinoma cells (786-O and A498) (Oda et al., 2010; Cormerais et al., 2016; Salisbury and Arthur, 2018). These outcomes emphasize that the overexpression of LAT1 is a frequently observed phenomenon in the process of mTORC1 pathway-associated 
cancer transformation. The activation of the hypoxia-inducible factor $2 \alpha$ (HIF-2 $\alpha$ ) pathway can likewise promote the expression of LAT1, thus increasing mTORC1 phosphorylation and activating $\mathrm{mTORC} 1$ in the process of cancer progression. Under the condition of oxygen deficiency, mTORC1 activity is generally restrained, which is a mechanism for saving energy through inhibiting mTORC1-related metabolism. The regulatory effect of HIF- $2 \alpha$ on LAT1 expression provides a molecular mechanism for the increased level of LAT1 in cancer cells. Sequence analysis shows that the proximal promoter of human LAT1 contains two HIF- $2 \alpha$ binding sites at -112 and -458 . In renal carcinoma cells and normal liver and lung cells, HIF- $2 \alpha$ binds directly to LAT1 through its DNA-binding region, thus participating in LAT1 gene expression and activating mTORC1 signal transduction (Elorza et al., 2012). Hypoxia-inducible factor $1 \alpha$ (HIF-1 $\alpha$ ) can stimulate angiogenesis and glycolytic enzyme transcription and is a downstream component of the mTOR pathway. HIF- $1 \alpha$ may regulate the expression of LAT1, which has a notable correlation with HIF-1 $\alpha$ in non-small cell lung cancer (Kaira et al., 2011b). Consequently, LAT1 is involved in cancer development and invasion through the mTOR pathway by providing nutrients and participating in oxygen regulation and autophagy. LAT1 can increase the intracellular supply of leucine and then activate the mTORC1 pathway, which is essential for regulating CTL differentiation, memory, and migratory capacity (Araki et al., 2009; Zheng et al., 2009; Powell and Delgoffe, 2010; Rao et al., 2010). In patients with rheumatoid arthritis (RA), LAT1 is upregulated in the synovium. The RNA interference method was used to study the effect of LAT1 gene inhibition on the synovial fibroblast-like cells (FLS) of patients with RA to explore its effect on RA. SiRNA interference with LAT1 decreases the phosphorylation of mTOR with its downstream target 4EBP1, uptake of leucine, and migratory capability of RA FLS. Cells treated with the inflammatory cytokine IL-17 stimulate LAT1 expression and participate in the LAT1-mediated migration of fibroblasts. By contrast, the promoting effect of IL-17 on LAT1 is neutralized by the application of the mTOR signal inhibitor temsirolimus or eIF4E inhibitors. SiLAT1 also significantly reduces IL-17-mediated leucine absorption and cell migration. In conclusion, LAT1 overexpression induced by IL-17 through the mTOR/4EBP1 pathway aggravates FLS migration in RA (Yu et al., 2018). Similar to amino acids that regulate the mTOR pathway, some hormones, such as insulin and insulin-like growth factor-1 (IGF-1), serve as essential upstream mediators of mTORC1 signaling. When insulin or IGF-1 receptor binds to a ligand, mTORC1 can be activated, which increases protein synthesis (Kandasamy et al., 2018). The dysregulation of LAT1 and MTOR is also related to obesity and T2D (Cohen and Hall, 2009). Mucosa-associated invariant T (MAIT) cells significantly upregulate their glycolysis rate in an mTORC1-dependent manner during activation. This behavior is crucial for the normal function of MAIT cells. MAIT cells isolated from obese adults all present glycolysis, mTORC1 signal, and LAT1 transport defects (O'Brien et al., 2019). Muscle-specific LAT1 knockout mice show slight insulin resistance and reduced mTORC1 pathway activation in their skeletal muscle after being fed a highprotein diet (Taylor, 2014). Moreover, compared with control mice, muscle-specific LAT1 knockout mice exhibit slightly increased insulin resistance in a variety of dietary patterns. This characteristic suggests that insulin signaling is related to the expression of LAT1 in muscle tissue and may be associated with the potential activation abilities of leucine, the concentration of BCAA, and the flux of LAT1 substrates for the MTORC1 pathway (Poncet et al., 2014). As can be concluded from the above results, LAT1 is involved in cancer, immune response, and insulin signal regulation through the mTOR pathway. However, the detailed mechanism of this involvement needs further study.

\section{LAT1 and MYC}

MYC genes are among the oncogenes that were the first to be discovered, including c-Myc, n-Myc, and l-Myc. LAT1 not only participates in the activation of mTORC1 but is also associated with the expression of MYC in cancer cells. c-Myc is a vital positive mediator of LAT1. The LAT1 promoter has a typical cMyc binding site (Blackwell et al., 1990), and the overexpression of this oncogene leads to an increase in LAT1 expression. siRNA decreases the expression of c-Myc, which leads to a decrement in LAT1 protein and mRNA levels and then causes obvious leucine absorption deficiency in pancreatic cancer cells. c-Myc is an essential transcription factor for LAT1 regulation (Hayashi et al., 2012). MYC upregulates the levels of tryptophan and tryptophan metabolites in the kynurenine pathway by inducing the expression of the tryptophan transporter LAT1 and increasing the expression of the enzyme arylformamidase (AFMID), which promotes the conversion of tryptophan into tyrosine. LAT1 and AFMID levels increase in colon cancer cells and tissues, and kynurenine levels in tumor samples are higher than those in the adjacent normal tissues of patients with colon cancer. Abnormal LAT1 expression regulated by MYC plays an important role in colon cancer (Venkateswaran et al., 2019). LAT1 and MYC can promote each other's expression and activity in Burkitt's lymphoma and neuroblastoma cells. In a study on the influence of LAT1 on the metabolic pathway of MYC, the results indicated that MYC promotes the expression of LAT1 and, after MYC silencing, LAT1 mRNA and protein levels decrease significantly. The inhibition of LAT1 expression can significantly reduce the growth of Burkitt lymphoma and neuroblastoma cells, suggesting that MYC-induced LAT1 is closely related to tumor cell proliferation (Yue et al., 2017). Subsequently, LAT1- and MYC-knockout Burkitt lymphoma cells were subjected to gene expression profiling. The changes in gene expression after LAT1 knockout are likely caused by the decrease in MYC protein expression in LAT1 silencing cells. These results indicate that LAT1 and MYC regulate Burkitt lymphoma cell proliferation together (Salisbury and Arthur, 2018). Thus, LAT1 may be involved in the onset and progression of tumors through its interaction with the oncogene MYC.

\section{APPLICATION OF LAT1 IN THE DIAGNOSIS}

Auxiliary examination technology targeting LAT1 to detect tumors has gradually developed in recent years. The knowledge of LAT1 overexpression and substrate specificity has been used in the development of radiolabeled probes for cancer 
diagnosis. Labeling $\left[{ }^{18} \mathrm{~F}\right]$ or $\left[{ }^{11} \mathrm{C}\right]$ in the basal structure of LAT1 allows positron emission computed tomography (PET) imaging of compounds accumulated in the tumor after administration. Thus, several amino acids based probes have been developed including (S)-2-amino-3-[3(2- $\left[{ }^{18} \mathrm{~F}\right]$-fluoroethoxy)-4-iodophenyl $]-2$-methyl propanoic acid $\left(\left[{ }^{18} \mathrm{~F}\right]\right.$-FIMP), L-3- $\left[{ }^{18} \mathrm{~F}\right]$-fluoro- $\alpha$-methyl tyrosine $\left(\left[{ }^{18} \mathrm{~F}\right]-\mathrm{FAMT}\right)$, 6 - $\left[{ }^{18} \mathrm{~F}\right]$-fluoro-L-3,4-dihydroxy-phenylalanine ([ $\left.\left.{ }^{18} \mathrm{~F}\right]-\mathrm{DOPA}\right)$, $\mathrm{L}-\left[{ }^{11} \mathrm{C}\right]$-methyl-methionine $\left(\left[{ }^{11} \mathrm{C}\right]-\mathrm{MET}\right)$ and $\mathrm{O}-\left(2-\left[{ }^{18} \mathrm{~F}\right]-\right.$ fluoroethyl)-L-tyrosine ([ $\left.\left.{ }^{18} \mathrm{~F}\right]-\mathrm{FET}\right)$ (Puris et al., 2020). For example, in the LAT1-specific PET probe, FAMT is specifically accumulated in the site of malignant tumors. FAMT does not appear in non-cancerous areas, such as sarcoidosis and inflammatory lesions. The accumulation level of FAMT in PET images is closely related to the expression level of LAT1 in malignant tumors (Nobusawa et al., 2013). Therefore, LAT1-specific probes can be used to distinguish tumors from granulomatous and inflammatory benign lesions. Moreover, FAMT-PET probes prove that the levels of LAT1 in cell membranes are specific to human cancers. These molecular probes have a strong affinity for LAT1 because of their $\alpha$ methyl moieties. Given that $\alpha$-methylated aromatic amino acids, such as $\alpha$-methylphenylalanine, $\alpha$-methyltyrosine, and $\alpha$-methyldopa, specifically target LAT1 but have little influence on LAT2-regulated absorption, they are highly selective for LAT1 (Morimoto et al., 2008). Thus, given its excellent selectivity for LAT1, FAMT is used as an LAT1-specific probe that can be applied to find cancer through PET imaging (Kandasamy et al., 2018). The other probe $\left[{ }^{11} \mathrm{C}\right]-\mathrm{MET}$ has high specificity in the detection, qualitative diagnosis of tumor because of its convenient synthesis, rapid and strong specificity, and has become the most commonly used radiolabeled method (Tsukada et al., 2006; Glaudemans et al., 2013). In the research of Okubo et al. indicated that uptake of $\left[{ }^{11} \mathrm{C}\right]-\mathrm{MET}$ in human newly diagnosed gliomas was associated with the extent of LAT1 expression (Okubo et al., 2010). LAT1 targeted anticancer drugs have been used in boron neutron capture therapy (BNCT), mainly for patients with high-grade gliomas (Kawabata et al., 2009; Kankaanranta et al., 2011). BNCT is a kind of radiotherapy based on nuclear fission reaction. When ${ }^{10} \mathrm{~B}$ is irradiated by low-energy thermal neutron beam, high-energy alpha particle $\left({ }^{4} \mathrm{He}^{2+}\right)$ and recoil lithium $\left({ }^{7} \mathrm{Li}\right)$ nucleus, the nuclear fission reaction occurs (Barth et al., 2005). The efficacy of BNCT depends on the accumulation of ${ }^{10} \mathrm{~B}$ in cancer tissue, which can be improved by LAT1-mediated transmission. Overall, these findings provide a new idea for specific non-invasive tumor location and targeted tumor injection treatment, which may lead toward a new trend of tumor diagnosis and treatment in the future.

\section{APPLICATION OF LAT1 IN THE TREATMENT}

In tumor therapy, many cytotoxic anticancer drugs exert an antitumor effect by interfering with the biosynthesis and function of nucleic acids. However, these anticancer drugs have cytotoxic effects on cancer and normal cells, thus causing adverse reactions, such as myelosuppression, gastrointestinal disorders, and renal dysfunction (Rosenberg et al., 1969; Capranico et al., 1990; Rowinsky et al., 1990). As mentioned before, LAT1 has broad application prospects as a biomarker for tumor diagnosis, a molecular target for chemotherapy, and a selective target for radiotherapy (Nawashiro et al., 2006; Kim et al., 2008; Kaira et al., 2009c). Given that knocking out LAT1 can inhibit tumor proliferation and invasion, some scholars have begun to explore the effect of LAT1 inhibitors on tumors. The production of LAT inhibitors mainly concentrates on compounds mimicking LAT substrates so they can compete for amino acid binding. For example, the leucine analog BCH (2-aminobicyclo- (Broer, 2002; Bhutia et al., 2015)-heptane-2-carboxylic acid) can inhibit amino acid uptake in tumor cells (Mastroberardino et al., 1998; Kim et al., 2002). With members of the LAT1 family sharing most substrates, $\mathrm{BCH}$ can be used to block LAT family members that are undesirable for application in clinical treatment (Wang and Holst, 2015). Amino acid transport assay, DNA fragmentation analysis, and terminal deoxynucleotidyl transferase-mediated dUTP nick end labeling (TUNEL) assay have been used to study the inhibitory effects and mechanism of $\mathrm{BCH}$ on cancer cells. $\mathrm{BCH}$ decreases the growth and L-leucine transport of $\mathrm{KB}$ human oral epidermoid carcinoma cells, Saos2 human osteosarcoma cells, and C6 rat glioma cells in a time- and concentrationdependent manner. Meanwhile, after $\mathrm{BCH}$ treatment, DNA ladder structures appear and TUNEL-positive cells increase, suggesting cancer cell death. Caspase is a family of proteolytic enzymes that is a key player of apoptosis. Caspase enzymes are synthesized into inactive protoenzymes and require the activation of proteolytic enzymes (Datta et al., 1997). Procapase7 levels in cancer cells without $\mathrm{BCH}$ treatment are low and decreased in $\mathrm{KB}$, Saos2, and C6 cells after BCH treatment. $\mathrm{BCH}$ treatment also promotes the proteolysis of procaspase- 3 in KB and C6 cells (Datta et al., 1997). These results indicate that $\mathrm{BCH}$ inhibits LAT1 activity in cells and causes EAA loss, which leads to cancer cell apoptosis (Kim et al., 2008). BCH promotes cancer cell apoptosis by activating caspase and inhibits DNA synthesis by promoting the expression of the cyclindependent kinase inhibitors p21 and p27, thus playing a role in cytostatic and cytocidal influences on human malignant glioma cells with positive LAT1 expression (Kobayashi et al., 2008). The expression of LAT1 in human ovarian cancer cell lines SKOV3, IGROV1, A2780, and OVCAR3 is considerably higher than that in the normal ovarian epithelial cell line IOSE397. $\mathrm{BCH}$ significantly inhibits the proliferation, migration, and Lleucine uptake of OVCAR-3 cells (Kaji et al., 2010). BCH also decreases the phosphorylation of p70S6K, a downstream effector of mTOR, in SKOV3 and IGROV1 cells and significantly reduces the proliferation of these two cell lines. Finally, BCH increases the sensitivity of IGROV1 and A2780 cells to bestatin, an antiproliferative aminopeptidase inhibitor, and induces the inhibition of cancer cell proliferation. These effects suggest that combined therapy has a synergistic effect. Hence, LAT1 may be the target of combined antiproliferative aminopeptidase inhibitors in the treatment of ovarian cancer (Fan et al., 2010). Yamauchi et al. (2009) also suggested that BCH increases the 
antitumor capability of cisplatin in a head and neck squamous cell carcinoma cell line. However, if $\mathrm{BCH}$ acts on normal living cells, then the amino acids that are indispensable to protein synthesis and cell growth and metabolism may become deficient, leading to cell damage.

The treatment of cells with the LAT1 inhibitor BCH also decreases glucose levels and relieves insulin resistance. The mitochondrial membrane potential and ATP production of islet $\beta$ cells exposed to high concentrations of glucose and free fatty acids are significantly reduced (El-Assaad et al., 2010). These effects are believed to promote the development of T2D by impairing $\beta$ cell function and causing $\beta$ cell apoptosis and are generally known as $\beta$ cell glycolipidoxicity (El-Assaad et al., 2003; Poitout and Robertson, 2008). In an in vivo study, 7-week-old diabetic $\mathrm{db} / \mathrm{db}$ mice received $\mathrm{BCH}$ and placebo treatment for 6 weeks. After treatment, all the mice were subjected to the intraperitoneal glucose tolerance test (IPGTT) and immunohistological examinations. The IPGTT revealed that the mice in the $\mathrm{db} / \mathrm{db}$ control group exhibited significant glucose intolerance. Interestingly, the $\mathrm{BCH}$ treatment group presented significantly increased glucose tolerance and insulin secretion. Moreover, in the $\mathrm{db} / \mathrm{db}$ control group, islets were destroyed, stained $\beta$ cells decreased, and glucagon-positive $\alpha$-cells that penetrated into the whole islets appeared. The morphology of the islet cells of the $\mathrm{db} / \mathrm{db}$ mice treated with $\mathrm{BCH}$ was relatively normal, the number of $\alpha$ cells in islet cores was significantly reduced, the ratio of insulin-positive $\beta$ cells among the total area of islets increased, and the percentage of $\beta$ cells expressing caspase 3 decreased. These studies showed that $\mathrm{BCH}$ can enhance $\beta$ cell function and avoid $\beta$ cell apoptosis in diabetic $\mathrm{db} / \mathrm{db}$ mice (Han et al., 2012). Another study showed that BCH increases insulin secretion induced by low glucose and high glucose (HG) by 1.8 and 1.2 times, respectively. Culturing $\beta$ cells under HG conditions for a period of time can reduce insulin concentration, whereas $\mathrm{BCH}$ treatment can restore the HG-mediated decrease in insulin concentration. $\mathrm{BCH}$ also blocks the inhibition of glucose-stimulated insulin secretion induced by $\mathrm{HG}$ and the decrease of insulin gene expression induced by HG/palmitic acid (PA). $\mathrm{BCH}$ also has a concentration-dependent protective effect on HG/PA-induced DNA fragmentation. The C-Jun N-terminal kinase (JNK) pathway is an important regulator of endoplasmic reticulum (ER) stress induced by fatty acids. Glucose can enhance JNK phosphorylation during ER stress induced by PA and induce $\beta$ cell apoptosis (Martinez et al., 2008; Bachar et al., 2009). $\mathrm{BCH}$ can reduce HG/PA-stimulated phospho-JNK levels with a concentration-dependent pattern. Furthermore, the long-term $\mathrm{BCH}$ treatment of mice can improve most of the metabolic changes caused by a high fat/high fructose (HF/HFr) diet. Numerous stress and inflammation-related signals, such as JNK, p38, pancreatic endoplasmic reticulum kinase (PERK), and NF$\kappa \mathrm{B}$, have been proven to be related to insulin resistance and liver injury induced by a Western diet. A study suggested that $\mathrm{BCH}$ can prevent the $\mathrm{HF} / \mathrm{HFr}$-stimulated accumulation of adipose and the activation of stress and inflammatory pathways in liver tissue. For example, $\mathrm{BCH}$ reduces the level of phosphorylated JNK, phosphorylated PERK, phosphorylated p38, and phosphorylated NF- $\kappa$ B. BCH likewise decreases the expressions of TNF- $\alpha$ and
IL- $1 \beta$ in the liver and the contents of alanine transaminase and aspartate transaminase in the liver collagen and plasma of $\mathrm{HF} / \mathrm{HFr}$ mice. Compared with the control diet, the HF/HFr diet upregulates fasting blood glucose by $\sim 43 \%$. BCH treatment restores the elevated fasting blood glucose levels caused by $\mathrm{HF} / \mathrm{HFr}$ to close to the blood glucose level of the control group and improves glucose tolerance. These results indicate that stress, inflammation, and toxicity pathways stimulated by long-term $\mathrm{HF} / \mathrm{HFr}$ diet can be prevented by $\mathrm{BCH}$, which can be used as a strategy to prevent non-alcoholic fatty liver disease and T2D caused by a high-calorie Western diet (Ruderman et al., 2010; Houtkooper et al., 2012; Han et al., 2016). The LAT1 inhibitor $\mathrm{BCH}$ can not only inhibit cancer cell proliferation and induce cancer cell apoptosis but also improve insulin resistance and relieve inflammation. However, $\mathrm{BCH}$ cannot be used in the clinic because of its low specificity and possible side effects. Thus, the discovery of an LAT1 inhibitor with similar effects as $\mathrm{BCH}$ has become an urgent problem that must be solved.

Several new compounds that can specifically inhibit LAT1 have been generated through synthetic chemistry and in vitro screening. These compounds include the novel tyrosine analog JPH203, (S)-2-amino-3(4-[(Bhutia et al., 2015) meth-oxy]-3,5dichlorophenyl) propanoic acid, which is also called KYT-0353 and SKN103. SKN103 was synthesized based on the structure of T3 which displayed inhibite the proliferation of pancreatic cancer cells and squamous cell carcinoma cells (Kongpracha et al., 2017). JPH203 suppresses LAT1 through substrate competition (Yun et al., 2014). The microenvironment of the nude mouse system used for JPH203 therapeutic assessment is akin to that of human tumors, illustrating that JPH203 may have clinical efficacy in humans (Oda et al., 2010). Therefore, JPH203, a new LAT1specific inhibitor, has become a potential tumor chemotherapy drug. Surprisingly, JPH203 does not damage normal murine thymocytes, lymphocytes, erythrocytes, platelets, bone marrow mature cells, stem cells, and early progenitors (Yun et al., 2014; Hayashi and Anzai, 2017). It may inhibit the activation of mTORC1 and the level of c-Myc in T-ALL and T-cell lymphoblastic lymphoma. JPH203 can also significantly inhibit the activity of T-ALL cells. It reduces the survival rate of T-ALL cells from mice and patients in vitro and inhibits the growth of T-ALL tumors in mice. Meanwhile, it has no effect on the viability of normal $\mathrm{T}$ cells or other types of blood cells (Rosilio et al., 2015). Other research showed that JPH203 inhibits leucine absorption and cell proliferation in human colon cancer-derived HT-29 cells and mouse renal proximal tubule cells. Moreover, the intravenous injections of 12.5 and $25.0 \mathrm{mg} / \mathrm{kg} \mathrm{JPH} 203$ have a significant inhibitory effect on HT-29 tumors transplanted into nude mice, with the maximum inhibitory rates of 65.9 and $77.2 \%$, respectively. However, weight gain, which is a symbol of security, has negligibly decreased. Thus, although JPH203 can obviously inhibit the growth of HT-29 cells in vitro and in vivo, it only results in slight weight loss (Oda et al., 2010). Given that the specific LAT1 inhibitor JPH203 has been proven to inhibit the growth of tumor cells and has little effect on other cells, it is expected to become a new antitumor drug in the clinic. However, the clinical use of JPH203 needs further clinical verification. Meanwhile, the effects of other LAT1 inhibitors on immunity, 
inflammation, and insulin-resistance-related diseases have not been studied yet and are thus new directions for future research.

In the past few years, the potential of LAT1 to enhance the entry of nanoparticles into cancer cells has been studied to treat cancer. In the studies of $\mathrm{Li}$ et al, nanoparticles were conjugated with glutamate as ligand for LAT1. The result showed that the antitumor efficiency of glutamic acid conjugated paclitaxel nanoparticles (SPG25 NPs) in vitro and in vivo was higher than that of unconjugated nanoparticles (Li et al., 2017). Similarly, in the other study of the same team, glutamate-conjugated docetaxelloaded liposomes showed an increased cytotoxicity in vitro and higher accumulation in the brain compared to unconjugated liposomes ( $\mathrm{Li}$ et al., 2016).In another words, Ong et al. found that the combination of levodopa and anisotropic gold nanoparticles (AuNPs) mediated selective photothermal ablation of breast cancer cells and chemosensitized cells (Ong et al., 2017). In conclusion, these recent studies suggest that LAT1 targeting nanoparticles may be a promising method to improve the efficacy of nanoparticles.

\section{CONCLUSION}

LAT1, an AAT, transports amino acids and regulates a variety of cell growth and metabolic processes. The main mechanisms related to LAT1 are illustrated in Figure 1. Fundamental research on LAT1 has made rapid progress since the importance of LAT1 in tumor cells was confirmed. LAT1 currently has broad application prospects as a biomarker for tumor and other diseases diagnosis, a molecular target for chemotherapy, and a selective target for diseases therapy. In recent years, many scholars worldwide have found highly effective and selective

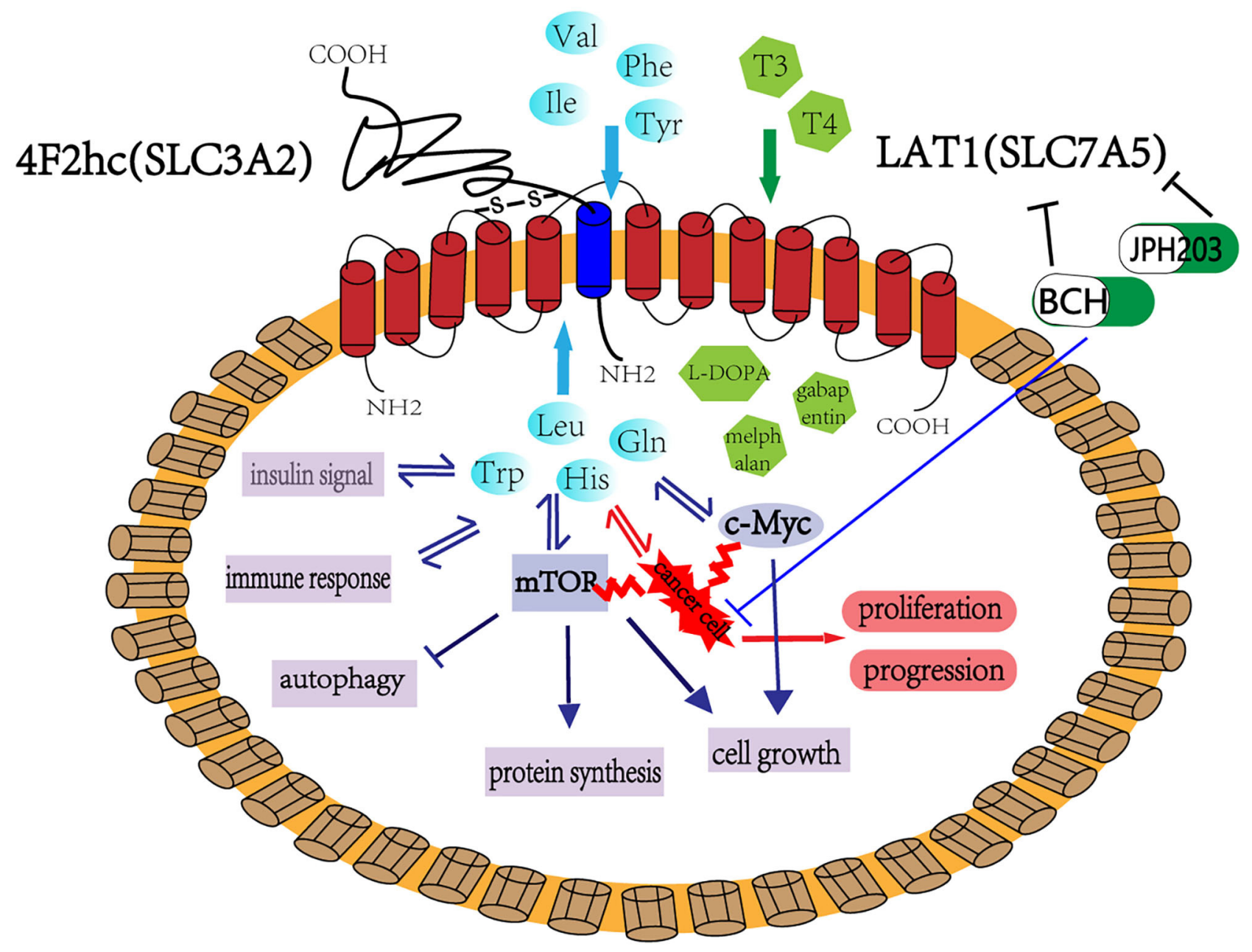

FIGURE 1 | LAT1 binds with 4F2hc (SLC3A2), which are located on the plasma membrane. This complex is responsible for transporting amino acids, hormones, and some drugs. LAT1 regulates cell growth and metabolism through the mTOR and MYC pathway and participates in insulin signaling, immune response, and cell autophagy. LAT1 also plays an important role in tumor occurrence and development. BCH and JPH2O3 are the two main inhibitors of LAT1, which can inhibit the growth of tumor cells and has considerable application prospect in tumor treatment. 
LAT1 inhibitors that have presented good anticancer effects in preclinical and clinical research. In particular, the latest phase of clinical trials has shown that JPH203 is effective for biliary tract cancer (Okano et al., 2020). The role of LAT1 has been gradually confirmed not only in tumors but also in inflammatory reactions, immune responses, insulin resistance, and other diseases. However, the mechanisms of the function of LAT1 in these diseases has not been clarified and the role of LAT1 inhibitors in diseases has not been studied. In the future, our task is to further confirm the role of several specific inhibitors of LAT1 in the treatment of various tumors and study its therapeutic effects on inflammation, immune-abnormal diseases, and insulin

\section{REFERENCES}

Adeva, M. M., Calvino, J., Souto, G., and Donapetry, C. (2012). Insulin resistance and the metabolism of branched-chain amino acids in humans. Amino Acids 43, 171-181. doi: 10.1007/s00726-011-1088-7

Aifantis, I., Raetz, E., and Buonamici, S. (2008). Molecular pathogenesis of T-cell leukaemia and lymphoma. Nat. Rev. Immunol. 8, 380-390. doi: 10.1038/nri2304

Al-Otaish, H., Al-Ayadhi, L., Bjorklund, G., Chirumbolo, S., Urbina, M. A., and El-Ansary, A. (2018). Relationship between absolute and relative ratios of glutamate, glutamine and GABA and severity of autism spectrum disorder. Metab. Brain Dis. 33, 843-854. doi: 10.1007/s11011-018-0186-6

Araki, K., Turner, A. P., Shaffer, V. O., Gangappa, S., Keller, S. A., Bachmann, M. F., et al. (2009). mTOR regulates memory CD8 T-cell differentiation. Nature 460, 108-112. doi: $10.1038 /$ nature 08155

Arnsburg, K., and Kirstein-Miles, J. (2014). Interrelation between protein synthesis, proteostasis and life span. Curr. Genomics 15, 66-75. doi: $10.2174 / 1389202915666140210210542$

Asano, S., Kameyama, M., Oura, A., Morisato, A., Sakai, H., Tabuchi, Y., et al. (2007). L-type amino acid transporter-1 expressed in human astrocytomas, U343MGa. Biol. Pharm. Bull. 30, 415-422. doi: 10.1248/bpb.30.415

Asor, E., Stempler, S., Avital, A., Klein, E., Ruppin, E., and Ben-Shachar, D. (2015). The role of branched chain amino acid and tryptophan metabolism in rat's behavioral diversity: Intertwined peripheral and brain effects. Eur. Neuropsychopharmacol. 25, 1695-1705. doi: 10.1016/j.euroneuro.2015. 07.009

Bachar, E., Ariav, Y., Ketzinel-Gilad, M., Cerasi, E., Kaiser, N., and Leibowitz, G. (2009). Glucose amplifies fatty acid-induced endoplasmic reticulum stress in pancreatic beta-cells via activation of mTORC1. PLOS ONE 4:e4954. doi: 10.1371/journal.pone.0004954

Barth, R. F., Coderre, J. A., Vicente, M. G., and Blue, T. E. (2005). Boron neutron capture therapy of cancer: current status and future prospects. Clin. Cancer Res. 11, 3987-4002. doi: 10.1158/1078-0432.CCR-05-0035

Bartlett, J. M., Thomas, J., Ross, D. T., Seitz, R. S., Ring, B. Z., Beck, R. A., et al. (2010). Mammostrat as a tool to stratify breast cancer patients at risk of recurrence during endocrine therapy. Breast Cancer Res. 12:R47. doi: $10.1186 / \mathrm{bcr} 2604$

Betsunoh, H., Fukuda, T., Anzai, N., Nishihara, D., Mizuno, T., Yuki, H., et al. (2013). Increased expression of system large amino acid transporter (LAT)-1 mRNA is associated with invasive potential and unfavorable prognosis of human clear cell renal cell carcinoma. BMC Cancer 13:509. doi: 10.1186/1471-2407-13-509

Bhutia, Y. D., Babu, E., Ramachandran, S., and Ganapathy, V. (2015). Amino Acid transporters in cancer and their relevance to "glutamine addiction": novel targets for the design of a new class of anticancer drugs. Cancer Res. 75, 1782-1788. doi: 10.1158/0008-5472.CAN-14-3745

Bik-Multanowski, M., and Pietrzyk, J. J. (2006). LAT1 gene variants-potential factors influencing the clinical course of phenylketonuria. J. Inherit. Metab. Dis. 29:684. doi: 10.1007/s10545-006-0285-0

Blackwell, T. K., Kretzner, L., Blackwood, E. M., Eisenman, R. N., and Weintraub, H. (1990). Sequence-specific DNA binding by the c-Myc protein. Science 250, 1149-1151. doi: 10.1126/science.2251503 resistance to provide a new concept for the treatment of LAT1related diseases.

\section{AUTHOR CONTRIBUTIONS}

JZ, YX, DL, LF, XZ, and YB performed literature searches and selected the studies and reviews discussed in the manuscript. The first draft of the manuscript was prepared by JZ. LZ performed subsequent amendments. JZ and YX revised the manuscript. All authors read and approved the final manuscript. All of the authors contributed to the conception of the review.

Broer, S. (2002). Adaptation of plasma membrane amino acid transport mechanisms to physiological demands. Pflugers Arch. 444, 457-466. doi: 10.1007/s00424-002-0840-y

Capranico, G., Zunino, F., Kohn, K. W., and Pommier, Y. (1990). Sequenceselective topoisomerase II inhibition by anthracycline derivatives in SV40 DNA: relationship with DNA binding affinity and cytotoxicity. Biochemistry 29, 562-569. doi: 10.1021/bi00454a033

Chen, R., Zou, Y., Mao, D., Sun, D., Gao, G., Shi, J., et al. (2014). The general amino acid control pathway regulates mTOR and autophagy during serum/glutamine starvation. J. Cell Biol. 206, 173-182. doi: 10.1083/jcb.201403009

Cheng, L., Lu, W., Kulkarni, B., Pejovic, T., Yan, X., Chiang, J. H., et al. (2010). Analysis of chemotherapy response programs in ovarian cancers by the next-generation sequencing technologies. Gynecol. Oncol. 117, 159-169. doi: 10.1016/j.ygyno.2010.01.041

Cheng, Q., Beltran, V. D., Chan, S. M., Brown, J. R., Bevington, A., and Herbert, T. P. (2016). System-L amino acid transporters play a key role in pancreatic beta-cell signalling and function. J. Mol. Endocrinol. 56, 175-187. doi: 10.1530/JME-15-0212

Cibrian, D., Castillo-Gonzalez, R., Fernandez-Gallego, N., de la Fuente, H., Jorge, I., Saiz, M. L., et al. (2020). Targeting L-type amino acid transporter 1 in innate and adaptive $\mathrm{T}$ cells efficiently controls skin inflammation. J. Allergy Clin. Immunol. 145, 199-214.e11. doi: 10.1016/j.jaci.2019.09.025

Cohen, A., and Hall, M. N. (2009). An amino acid shuffle activates mTORC1. Cell 136, 399-400. doi: 10.1016/j.cell.2009.01.021

Cormerais, Y., Giuliano, S., LeFloch, R., Front, B., Durivault, J., Tambutte, E., et al. (2016). Genetic disruption of the multifunctional CD98/LAT1 complex demonstrates the key role of essential amino acid transport in the control of mTORC1 and tumor growth. Cancer Res. 76, 4481-4492. doi: 10.1158/0008-5472.CAN-15-3376

Cornford, E. M., Young, D., Paxton, J. W., Finlay, G. J., Wilson, W. R., and Pardridge, W. M. (1992). Melphalan penetration of the blood-brain barrier via the neutral amino acid transporter in tumor-bearing brain. Cancer Res. $52,138-143$.

Datta, R., Kojima, H., Yoshida, K., and Kufe, D. (1997). Caspase-3-mediated cleavage of protein kinase $\mathrm{C}$ theta in induction of apoptosis. J. Biol. Chem. 272, 20317-20320. doi: 10.1074/jbc.272.33.20317

del Amo, E. M., Urtti, A., and Yliperttula, M. (2008). Pharmacokinetic role of Ltype amino acid transporters LAT1 and LAT2. Eur. J. Pharm. Sci. 35, 161-174. doi: 10.1016/j.ejps.2008.06.015

Dong, X. (2018). Current strategies for brain drug delivery. Theranostics 8, 1481-1493. doi: 10.7150/thno.21254

Duelli, R., Enerson, B. E., Gerhart, D. Z., and Drewes, L. R. (2000). Expression of large amino acid transporter LAT1 in rat brain endothelium. J. Cereb. Blood Flow Metab. 20, 1557-1562. doi: 10.1097/00004647-200011000-00005

El Ansari, R., Craze, M. L., Miligy, I., Diez-Rodriguez, M., Nolan, C. C., Ellis, I. O., et al. (2018). The amino acid transporter SLC7A5 confers a poor prognosis in the highly proliferative breast cancer subtypes and is a key therapeutic target in luminal B tumours. Breast Cancer Res. 20:21. doi: 10.1186/s13058-018-0946-6

El-Assaad, W., Buteau, J., Peyot, M. L., Nolan, C., Roduit, R., Hardy, S., et al. (2003). Saturated fatty acids synergize with elevated glucose to cause pancreatic beta-cell death. Endocrinology 144, 4154-4163. doi: 10.1210/en.2003-0410 
El-Assaad, W., Joly, E., Barbeau, A., Sladek, R., Buteau, J., Maestre, I., et al. (2010). Glucolipotoxicity alters lipid partitioning and causes mitochondrial dysfunction, cholesterol, and ceramide deposition and reactive oxygen species production in INS832/13 ss-cells. Endocrinology 151, 3061-3073. doi: 10.1210/en.2009-1238

Elorza, A., Soro-Arnaiz, I., Melendez-Rodriguez, F., Rodriguez-Vaello, V., Marsboom, G., de Carcer, G., et al. (2012). HIF2alpha acts as an mTORC1 activator through the amino acid carrier SLC7A5. Mol. Cell 48, 681-691. doi: 10.1016/j.molcel.2012.09.017

Fan, X., Ross, D. D., Arakawa, H., Ganapathy, V., Tamai, I., and Nakanishi, T. (2010). Impact of system L amino acid transporter 1 (LAT1) on proliferation of human ovarian cancer cells: a possible target for combination therapy with anti-proliferative aminopeptidase inhibitors. Biochem. Pharmacol. 80, 811-818. doi: 10.1016/j.bcp.2010.05.021

Friesema, E. C., Docter, R., Moerings, E. P., Verrey, F., Krenning, E. P., Hennemann, G., et al. (2001). Thyroid hormone transport by the heterodimeric human system L amino acid transporter. Endocrinology 142, 4339-4348. doi: 10.1210/endo.142.10.8418

Glaudemans, A. W., Enting, R. H., Heesters, M. A., Dierckx, R. A., van Rheenen, R. W., Walenkamp, A. M., et al. (2013). Value of 11C-methionine PET in imaging brain tumours and metastases. Eur. J. Nucl. Med. Mol. Imaging. 40, 615-635. doi: 10.1007/s00259-012-2295-5

Grzes, K. M., Swamy, M., Hukelmann, J. L., Emslie, E., Sinclair, L. V., and Cantrell, D. A. (2017). Control of amino acid transport coordinates metabolic reprogramming in T-cell malignancy. Leukemia 31, 2771-2779. doi: 10.1038/leu.2017.160

Gynther, M., Laine, K., Ropponen, J., Leppanen, J., Mannila, A., Nevalainen, T., et al. (2008). Large neutral amino acid transporter enables brain drug delivery via prodrugs. J. Med. Chem. 51, 932-936. doi: 10.1021/jm701175d

Gynther, M., Peura, L., Vernerova, M., Leppanen, J., Karkkainen, J., Lehtonen, M., et al. (2016a). Amino acid promoieties alter valproic acid pharmacokinetics and enable extended brain exposure. Neurochem. Res. 41, 2797-2809. doi: 10.1007/s11064-016-1996-8

Gynther, M., Pickering, D. S., Spicer, J. A., Denny, W. A., and Huttunen, K. M. (2016b). Systemic and brain pharmacokinetics of perforin inhibitor prodrugs. Mol. Pharm. 13, 2484-2491. doi: 10.1021/acs.molpharmaceut.6b00217

Hafliger, P., and Charles, R. P. (2019). The L-type amino acid transporter LAT1-an emerging target in cancer. Int. J. Mol. Sci. 20:2428. doi: 10.3390/ijms20102428

Haining, Z., Kawai, N., Miyake, K., Okada, M., Okubo, S., Zhang, X., et al. (2012). Relation of LAT1/4F2hc expression with pathological grade, proliferation and angiogenesis in human gliomas. BMC Clin. Pathol. 12:4. doi: 10.1186/1472-6890-12-4

Han, S. J., Choi, S. E., Yi, S. A., Jung, J. G., Jung, I. R., Shin, M., et al. (2016). Glutamate dehydrogenase activator $\mathrm{BCH}$ stimulating reductive amination prevents high fat/high fructose diet-induced steatohepatitis and hyperglycemia in C57BL/6J mice. Sci. Rep. 5:37468. doi: 10.1038/srep37468

Han, S. J., Choi, S. E., Yi, S. A., Lee, S. J., Kim, H. J., Kim, D. J., et al. (2012). betaCell-protective effect of 2-aminobicyclo-(2,2,1)-heptane-2-carboxylic acid as a glutamate dehydrogenase activator in $\mathrm{db} / \mathrm{db}$ mice. J. Endocrinol. 212, 307-315. doi: 10.1530/JOE-11-0340

Hara, K., Yonezawa, K., Kozlowski, M. T., Sugimoto, T., Andrabi, K., Weng, Q. P., et al. (1997). Regulation of eIF-4E BP1 phosphorylation by mTOR. J. Biol. Chem. 272, 26457-26463. doi: 10.1074/jbc.272.42.26457

Hasegawa, S., Ichiyama, T., Sonaka, I., Ohsaki, A., Okada, S., Wakiguchi, H., et al. (2012). Cysteine, histidine and glycine exhibit anti-inflammatory effects in human coronary arterial endothelial cells. Clin. Exp. Immunol. 167, 269-274. doi: 10.1111/j.1365-2249.2011.04519.x

Hashimoto, H., Kurata, A., Kikuchi, H., Masuda, Y., Fujita, K., Okuyama, R., et al. (2017). L-type amino acid transporter 1 expression in esophageal carcinogenesis according to WHO and Japanese classifications of intraepithelial neoplasia. Pathol. Int. 67, 247-255. doi: 10.1111/pin.12528

Hayase, S., Kumamoto, K., Saito, K., Kofunato, Y., Sato, Y., Okayama, H., et al. (2017). L-type amino acid transporter 1 expression is upregulated and associated with cellular proliferation in colorectal cancer. Oncol. Lett. 14, 7410-7416. doi: 10.3892/ol.2017.7148

Hayashi, K., and Anzai, N. (2017). Novel therapeutic approaches targeting L-type amino acid transporters for cancer treatment. World J. Gastrointest. Oncol. 9, 21-29. doi: 10.4251/wjgo.v9.i1.21
Hayashi, K., Jutabha, P., Endou, H., and Anzai, N. (2012). c-Myc is crucial for the expression of LAT1 in MIA Paca-2 human pancreatic cancer cells. Oncol. Rep. 28, 862-866. doi: 10.3892/or.2012.1878

Honjo, H., Kaira, K., Miyazaki, T., Yokobori, T., Kanai, Y., Nagamori, S., et al. (2016). Clinicopathological significance of LAT1 and ASCT2 in patients with surgically resected esophageal squamous cell carcinoma. J. Surg. Oncol. 113, 381-389. doi: $10.1002 /$ jso. 24160

Hosoya, K., and Tachikawa, M. (2009). Inner blood-retinal barrier transporters: role of retinal drug delivery. Pharm. Res. 26, 2055-2065. doi: 10.1007/s11095-009-9930-2

Hosoya, K., and Tomi, M. (2005). Advances in the cell biology of transport via the inner blood-retinal barrier: establishment of cell lines and transport functions. Biol. Pharm. Bull. 28, 1-8. doi: 10.1248/bpb.28.1

Houtkooper, R. H., Pirinen, E., and Auwerx, J. (2012). Sirtuins as regulators of metabolism and healthspan. Nat. Rev. Mol. Cell Biol. 13, 225-238. doi: $10.1038 / \mathrm{nrm} 3293$

Hundal, H. S., and Taylor, P. M. (2009). Amino acid transceptors: gate keepers of nutrient exchange and regulators of nutrient signaling. Am. J. Physiol. Endocrinol. Metab. 296, E603-E613. doi: 10.1152/ajpendo.91002.2008

Huttunen, J., Peltokangas, S., Gynther, M., Natunen, T., Hiltunen, M., Auriola, S., et al. (2019). L-type amino acid transporter 1 (LAT1/Lat1)-utilizing prodrugs can improve the delivery of drugs into neurons, astrocytes and microglia. Sci. Rep. 9:12860. doi: 10.1038/s41598-019-49009-z

Huttunen, K. M., Gynther, M., Huttunen, J., Puris, E., Spicer, J. A., and Denny, W. A. (2016). A selective and slowly reversible inhibitor of l-type amino acid transporter 1 (LAT1) potentiates antiproliferative drug efficacy in cancer cells. J. Med. Chem. 59, 5740-5751. doi: 10.1021/acs.jmedchem.6b00190

Ichinoe, M., Mikami, T., Yoshida, T., Igawa, I., Tsuruta, T., Nakada, N., et al. (2011). High expression of L-type amino-acid transporter 1 (LAT1) in gastric carcinomas: comparison with non-cancerous lesions. Pathol. Int. 61, 281-289. doi: 10.1111/j.1440-1827.2011.02650.x

Imai, H., Kaira, K., Oriuchi, N., Yanagitani, N., Sunaga, N., Ishizuka, T., et al. (2009). L-type amino acid transporter 1 expression is a prognostic marker in patients with surgically resected stage I non-small cell lung cancer. Histopathology 54, 804-813. doi: 10.1111/j.1365-2559.2009. 03300.x

Jacinto, E., Facchinetti, V., Liu, D., Soto, N., Wei, S., Jung, S. Y., et al. (2006). SIN1/MIP1 maintains rictor-mTOR complex integrity and regulates Akt phosphorylation and substrate specificity. Cell 127, 125-137. doi: 10.1016/j.cell.2006.08.033

Janpipatkul, K., Suksen, K., Borwornpinyo, S., Jearawiriyapaisarn, N., Hongeng, S., Piyachaturawat, P., et al. (2014). Downregulation of LAT1 expression suppresses cholangiocarcinoma cell invasion and migration. Cell. Signal 26, 1668-1679. doi: 10.1016/j.cellsig.2014.04.002

Jemal, A., Bray, F., Center, M. M., Ferlay, J., Ward, E., and Forman, D. (2011). Global cancer statistics. CA Cancer J. Clin. 61, 69-90. doi: 10.3322/caac.20107

Kageyama, T., Nakamura, M., Matsuo, A., Yamasaki, Y., Takakura, Y., Hashida, M., et al. (2000). The $4 \mathrm{~F} 2 \mathrm{hc} / \mathrm{LAT} 1$ complex transports L-DOPA across the bloodbrain barrier. Brain Res. 879, 115-121. doi: 10.1016/S0006-8993(00)02758-X

Kaira, K., Oriuchi, N., Imai, H., Shimizu, K., Yanagitani, N., Sunaga, N., et al. (2008a). Expression of L-type amino acid transporter 1 (LAT1) in neuroendocrine tumors of the lung. Pathol. Res. Pract. 204, 553-561. doi: 10.1016/j.prp.2008.02.003

Kaira, K., Oriuchi, N., Imai, H., Shimizu, K., Yanagitani, N., Sunaga, N., et al. (2008b). 1-type amino acid transporter 1 and CD98 expression in primary and metastatic sites of human neoplasms. Cancer Sci. 99, 2380-2386. doi: 10.1111/j.1349-7006.2008.00969.x

Kaira, K., Oriuchi, N., Imai, H., Shimizu, K., Yanagitani, N., Sunaga, N., et al. (2009a). L-type amino acid transporter 1 (LAT1) is frequently expressed in thymic carcinomas but is absent in thymomas. J. Surg. Oncol. 99, 433-438. doi: $10.1002 /$ jso. 21277

Kaira, K., Oriuchi, N., Imai, H., Shimizu, K., Yanagitani, N., Sunaga, N., et al. (2009b). Prognostic significance of L-type amino acid transporter 1 (LAT1) and $4 \mathrm{~F} 2$ heavy chain (CD98) expression in stage I pulmonary adenocarcinoma. Lung Cancer 66, 120-126. doi: 10.1016/j.lungcan.2008.12.015

Kaira, K., Oriuchi, N., Shimizu, K., Ishikita, T., Higuchi, T., Imai, H., et al. (2009c). Evaluation of thoracic tumors with (18)F-FMT and (18)F-FDG PET-CT: a clinicopathological study. Int. J. Cancer 124, 1152-1160. doi: 10.1002/ijc.24034 
Kaira, K., Oriuchi, N., Takahashi, T., Nakagawa, K., Ohde, Y., Okumura, T., et al. (2011b). LAT1 expression is closely associated with hypoxic markers and mTOR in resected non-small cell lung cancer. Am. J. Transl. Res. 3, 468-478. doi: $10.1177 / 1066896911429296$

Kaira, K., Sunose, Y., Arakawa, K., Ogawa, T., Sunaga, N., Shimizu, K., et al. (2012). Prognostic significance of L-type amino-acid transporter 1 expression in surgically resected pancreatic cancer. Br. J. Cancer 107, 632-638. doi: 10.1038/bjc.2012.310

Kaira, K., Sunose, Y., Ohshima, Y., Ishioka, N. S., Arakawa, K., Ogawa, T., et al. (2013a). Clinical significance of L-type amino acid transporter 1 expression as a prognostic marker and potential of new targeting therapy in biliary tract cancer. BMC Cancer 13:482. doi: 10.1186/1471-2407-13-482

Kaira, K., Toyoda, M., Shino, M., Sakakura, K., Takahashi, K., Tominaga, H., et al. (2013b). Clinicopathological significance of L-type amino acid transporter 1 (LAT1) expression in patients with adenoid cystic carcinoma. Pathol. Oncol. Res. 19, 649-656. doi: 10.1007/s12253-013-9624-2

Kaira, K., Oriuchi, N., Takahashi, T., Nakagawa, K., Ohde, Y., Okumura, T., et al. (2011a). L-type amino acid transporter 1 (LAT1) expression in malignant pleural mesothelioma. Anticancer Res. 31, 4075-4082.

Kaji, M., Kabir-Salmani, M., Anzai, N., Jin, C. J., Akimoto, Y., Horita, A., et al. (2010). Properties of L-type amino acid transporter 1 in epidermal ovarian cancer. Int. J. Gynecol. Cancer. 20, 329-336. doi: 10.1111/IGC.0b013e3181d28e13

Kanai, Y., Segawa, H., Miyamoto, K., Uchino, H., Takeda, E., and Endou, H. (1998). Expression cloning and characterization of a transporter for large neutral amino acids activated by the heavy chain of 4F2 antigen (CD98). J. Biol. Chem. 273, 23629-23632. doi: 10.1074/jbc.273.37.23629

Kandasamy, P., Gyimesi, G., Kanai, Y., and Hediger, M. A. (2018). Amino acid transporters revisited: New views in health and disease. Trends Biochem. Sci. 43, 752-789. doi: 10.1016/j.tibs.2018.05.003

Kankaanranta, L., Saarilahti, K., Makitie, A., Valimaki, P., Tenhunen, M., and Joensuu, H. (2011). Boron neutron capture therapy (BNCT) followed by intensity modulated chemoradiotherapy as primary treatment of large head and neck cancer with intracranial involvement. Radiother. Oncol. 99, 98-99. doi: 10.1016/j.radonc.2011.02.008

Kawabata, S., Miyatake, S., Kuroiwa, T., Yokoyama, K., Doi, A., Iida, K., et al. (2009). Boron neutron capture therapy for newly diagnosed glioblastoma. J. Radiat. Res. 50, 51-60. doi: 10.1269/jrr.08043

Kim, C. S., Cho, S. H., Chun, H. S., Lee, S. Y., Endou, H., Kanai, Y., et al. (2008). $\mathrm{BCH}$, an inhibitor of system $\mathrm{L}$ amino acid transporters, induces apoptosis in cancer cells. Biol. Pharm. Bull. 31, 1096-1100. doi: 10.1248/bpb.31.1096

Kim, D. K., Kanai, Y., Choi, H. W., Tangtrongsup, S., Chairoungdua, A., Babu, E., et al. (2002). Characterization of the system $\mathrm{L}$ amino acid transporter in T24 human bladder carcinoma cells. Biochim. Biophys. Acta 1565, 112-121. doi: 10.1016/S0005-2736(02)00516-3

Kim, D. K., Ahn, S. G., Park, J. C., Kanai, Y., Endou, H., and Yoon, J. H. (2004). Expression of L-type amino acid transporter 1 (LAT1) and 4F2 heavy chain $(4 \mathrm{~F} 2 \mathrm{hc})$ in oral squamous cell carcinoma and its precusor lesions. Anticancer Res. 24, 1671-1675.

Kobayashi, K., Ohnishi, A., Promsuk, J., Shimizu, S., Kanai, Y., Shiokawa, Y., et al. (2008). Enhanced tumor growth elicited by L-type amino acid transporter 1 in human malignant glioma cells. Neurosurgery 62, 493-503, discussion-4. doi: 10.1227/01.neu.0000316018.51292.19

Kongpracha, P., Nagamori, S., Wiriyasermkul, P., Tanaka, Y., Kaneda, K., Okuda, S., et al. (2017). Structure-activity relationship of a novel series of inhibitors for cancer type transporter L-type amino acid transporter 1 (LAT1). J. Pharmacol. Sci. 133, 96-102. doi: 10.1016/j.jphs.2017.01.006

Koshi, H., Sano, T., Handa, T., Yanagawa, T., Saitou, K., Nagamori, S., et al. (2015). L-type amino acid transporter-1 and CD98 expression in bone and soft tissue tumors. Pathol. Int. 65, 460-467. doi: 10.1111/pin.12323

Li, L., Di, X., Wu, M., Sun, Z., Zhong, L., Wang, Y., et al. (2017). Targeting tumor highly-expressed LAT1 transporter with amino acid-modified nanoparticles: Toward a novel active targeting strategy in breast cancer therapy. Nanomedicine 13, 987-998. doi: 10.1016/j.nano.2016.11.012

Li, L., Di, X., Zhang, S., Kan, Q., Liu, H., Lu, T., et al. (2016). Large amino acid transporter 1 mediated glutamate modified docetaxel-loaded liposomes for glioma targeting. Colloids Surf. B Biointerfaces 141, 260-267. doi: $10.1016 /$ j.colsurfb.2016.01.041
Lynch, C. J., and Adams, S. H. (2014). Branched-chain amino acids in metabolic signalling and insulin resistance. Nat. Rev. Endocrinol. 10, 723-736. doi: $10.1038 /$ nrendo.2014.171

Macotela, Y., Emanuelli, B., Bang, A. M., Espinoza, D. O., Boucher, J., Beebe, $\mathrm{K}$, et al. (2011). Dietary leucine-an environmental modifier of insulin resistance acting on multiple levels of metabolism. PLOS ONE 6:e21187. doi: 10.1371/journal.pone.0021187

Marshall, A. D., van Geldermalsen, M., Otte, N. J., Anderson, L. A., Lum, T., Vellozzi, M. A., et al. (2016). LAT1 is a putative therapeutic target in endometrioid endometrial carcinoma. Int. J. Cancer 139, 2529-2539. doi: $10.1002 /$ ijc. 30371

Martinez, S. C., Tanabe, K., Cras-Meneur, C., Abumrad, N. A., Bernal-Mizrachi, E., and Permutt, M. A. (2008). Inhibition of Foxol protects pancreatic islet betacells against fatty acid and endoplasmic reticulum stress-induced apoptosis. Diabetes 57, 846-859. doi: 10.2337/db07-0595

Mastroberardino, L., Spindler, B., Pfeiffer, R., Skelly, P. J., Loffing, J., Shoemaker, C. B., et al. (1998). Amino-acid transport by heterodimers of 4F2hc/CD98 and members of a permease family. Nature 395, 288-291. doi: 10.1038/26246

Milkereit, R., Persaud, A., Vanoaica, L., Guetg, A., Verrey, F., and Rotin, D. (2015). LAPTM4b recruits the LAT1-4F2hc Leu transporter to lysosomes and promotes mTORC1 activation. Nat. Commun. 6:7250. doi: $10.1038 /$ ncomms 8250

Moller, L. B., Paulsen, M., Koch, R., Moats, R., Guldberg, P., and Guttler, F. (2005). Inter-individual variation in brain phenylalanine concentration in patients with $\mathrm{PKU}$ is not caused by genetic variation in the $4 \mathrm{~F} 2 \mathrm{hc} / \mathrm{LAT} 1 \mathrm{complex}$. Mol. Genet. Metab. 86(Suppl. 1), S119-S123. doi: 10.1016/j.ymgme.2005.07.031

Morimoto, E., Kanai, Y., Kim, D. K., Chairoungdua, A., Choi, H. W., Wempe, M. F., et al. (2008). Establishment and characterization of mammalian cell lines stably expressing human L-type amino acid transporters. J. Pharmacol. Sci. 108, 505-516. doi: 10.1254/jphs.08232FP

Nakanishi, K., Matsuo, H., Kanai, Y., Endou, H., Hiroi, S., Tominaga, S., et al. (2006). LAT1 expression in normal lung and in atypical adenomatous hyperplasia and adenocarcinoma of the lung. Virchows Arch. 448, 142-150. doi: 10.1007/s00428-005-0063-7

Namikawa, M., Kakizaki, S., Kaira, K., Tojima, H., Yamazaki, Y., Horiguchi, N., et al. (2015). Expression of amino acid transporters (LAT1, ASCT2 and xCT) as clinical significance in hepatocellular carcinoma. Hepatol. Res. 45, 1014-1022. doi: 10.1111/hepr.12431

Nawashiro, H., Otani, N., Shinomiya, N., Fukui, S., Ooigawa, H., Shima, K., et al. (2006). L-type amino acid transporter 1 as a potential molecular target in human astrocytic tumors. Int. J. Cancer 119, 484-492. doi: 10.1002/ijc. 21866

Nicklin, P., Bergman, P., Zhang, B., Triantafellow, E., Wang, H., Nyfeler, B., et al. (2009). Bidirectional transport of amino acids regulates mTOR and autophagy. Cell 136, 521-534. doi: 10.1016/i.cell.2008.11.044

Nobusawa, A., Kim, M., Kaira, K., Miyashita, G., Negishi, A., Oriuchi, N., et al. (2013). Diagnostic usefulness of (1)(8)F-FAMT PET and L-type amino acid transporter 1 (LAT1) expression in oral squamous cell carcinoma. Eur. J. Nucl. Med. Mol. Imaging 40, 1692-1700. doi: 10.1007/s00259-013-2477-9

O’Brien, A., Loftus, R. M., Pisarska, M. M., Tobin, L. M., Bergin, R., Wood, N. A. W., et al. (2019). Obesity reduces mTORC1 activity in mucosal-associated invariant $\mathrm{T}$ cells, driving defective metabolic and functional responses. $J$. Immunol. 202, 3404-3411. doi: 10.4049/jimmunol.1801600

O'Connell, T. M. (2013). The complex role of branched chain amino acids in diabetes and cancer. Metabolites 3, 931-945. doi: 10.3390/metabo3040931

Oda, K., Hosoda, N., Endo, H., Saito, K., Tsujihara, K., Yamamura, M., et al. (2010). L-type amino acid transporter 1 inhibitors inhibit tumor cell growth. Cancer Sci. 101, 173-179. doi: 10.1111/j.1349-7006.2009.01386.x

Ohgaki, R., Ohmori, T., Hara, S., Nakagomi, S., Kanai-Azuma, M., KanedaNakashima, K., et al. (2017). Essential roles of L-type amino acid transporter 1 in syncytiotrophoblast development by presenting fusogenic 4F2hc. Mol. Cell. Biol. 37, e00427-e00416. doi: 10.1128/MCB.00427-16

Ohtsuki, S., Yamaguchi, H., Kang, Y. S., Hori, S., and Terasaki, T. (2010). Reduction of L-type amino acid transporter $1 \mathrm{mRNA}$ expression in brain capillaries in a mouse model of Parkinson's disease. Biol. Pharm. Bull. 33, 1250-1252. doi: 10.1248/bpb.33.1250

Okano, N., Naruge, D., Kawai, K., Kobayashi, T., Nagashima, F., Endou, H., et al. (2020). First-in-human phase I study of JPH203, an L-type amino acid 
transporter 1 inhibitor, in patients with advanced solid tumors. Invest. New Drugs 38, 1495-1506. doi: 10.1007/s10637-020-00924-3

Okubo, S., Zhen, H. N., Kawai, N., Nishiyama, Y., Haba, R., and Tamiya, T. (2010). Correlation of L-methyl-11C-methionine (MET) uptake with L-type amino acid transporter 1 in human gliomas. J. Neurooncol. 99, 217-225. doi: 10.1007/s11060-010-0117-9

Ong, Z. Y., Chen, S., Nabavi, E., Regoutz, A., Payne, D. J., Elson, D. S., et al. (2017). Multibranched gold nanoparticles with intrinsic LAT-1 targeting capabilities for selective photothermal therapy of breast cancer. ACS Appl. Mater. Interfaces 9, 39259-39270. doi: 10.1021/acsami.7b14851

Pantham, P., Rosario, F. J., Weintraub, S. T., Nathanielsz, P. W., Powell, T. L., Li, C., et al. (2016). Down-regulation of placental transport of amino acids precedes the development of intrauterine growth restriction in maternal nutrient restricted baboons. Biol. Reprod. 95:98. doi: 10.1095/biolreprod.116.141085

Poitout, V., and Robertson, R. P. (2008). Glucolipotoxicity: fuel excess and beta-cell dysfunction. Endocr. Rev. 29, 351-366. doi: 10.1210/er.2007-0023

Poncet, N., Mitchell, F. E., Ibrahim, A. F., McGuire, V. A., English, G., Arthur, J. S., et al. (2014). The catalytic subunit of the system L1 amino acid transporter (slc7a5) facilitates nutrient signalling in mouse skeletal muscle. PLoS ONE 9:e89547. doi: 10.1371/journal.pone.0089547

Powell, J. D., and Delgoffe, G. M. (2010). The mammalian target of rapamycin: linking T cell differentiation, function, and metabolism. Immunity 33, 301-311. doi: 10.1016/j.immuni.2010.09.002

Puris, E., Gynther, M., Auriola, S., and Huttunen, K. M. (2020). L-Type amino acid transporter 1 as a target for drug delivery. Pharm. Res. 37:88. doi: 10.1007/s11095-020-02826-8

Puris, E., Gynther, M., de Lange, E. C. M., Auriola, S., Hammarlund-Udenaes, M., Huttunen, K. M., et al. (2019a). Mechanistic study on the use of the l-type amino acid transporter 1 for brain intracellular delivery of ketoprofen via prodrug: a novel approach supporting the development of prodrugs for intracellular targets. Mol. Pharm. 16, 3261-3274. doi: 10.1021/acs.molpharmaceut.9b00502

Puris, E., Gynther, M., Huttunen, J., Auriola, S., and Huttunen, K. M. (2019b). L-type amino acid transporter 1 utilizing prodrugs of ferulic acid revealed structural features supporting the design of prodrugs for brain delivery. Eur. J. Pharm. Sci. 129, 99-109. doi: 10.1016/j.ejps.2019.01.002

Puris, E., Gynther, M., Huttunen, J., Petsalo, A., and Huttunen, K. M. (2017). Ltype amino acid transporter 1 utilizing prodrugs: how to achieve effective brain delivery and low systemic exposure of drugs. J. Control. Release 261, 93-104. doi: 10.1016/j.jconrel.2017.06.023

Rao, R. R., Li, Q., Odunsi, K., and Shrikant, P. A. (2010). The mTOR kinase determines effector versus memory CD8 $+\mathrm{T}$ cell fate by regulating the expression of transcription factors T-bet and Eomesodermin. Immunity 32, 67-78. doi: 10.1016/j.immuni.2009.10.010

Rooman, I., Lutz, C., Pinho, A. V., Huggel, K., Reding, T., Lahoutte, T., et al. (2013). Amino acid transporters expression in acinar cells is changed during acute pancreatitis. Pancreatology 13, 475-485. doi: 10.1016/j.pan.2013.06.006

Rosario, F. J., Kanai, Y., Powell, T. L., and Jansson, T. (2015). Increased placental nutrient transport in a novel mouse model of maternal obesity with fetal overgrowth. Obesity 23:, -1670. doi: 10.1002/oby.21165

Rosenberg, B., VanCamp, L., Trosko, J. E., and Mansour, V. H. (1969). Platinum compounds: a new class of potent antitumour agents. Nature 222, 385-386. doi: $10.1038 / 222385 \mathrm{a} 0$

Rosilio, C., Nebout, M., Imbert, V., Griessinger, E., Neffati, Z., Benadiba, J., et al. (2015). L-type amino-acid transporter 1 (LAT1): a therapeutic target supporting growth and survival of T-cell lymphoblastic lymphoma/T-cell acute lymphoblastic leukemia. Leukemia 29, 1253-1266. doi: 10.1038/leu.2014.338

Rowinsky, E. K., Cazenave, L. A., and Donehower, R. C. (1990). Taxol: a novel investigational antimicrotubule agent. J. Natl. Cancer Inst. 82, 1247-1259. doi: $10.1093 /$ jnci/82.15.1247

Ruderman, N. B., Xu, X. J., Nelson, L., Cacicedo, J. M., Saha, A. K., Lan, F., et al. (2010). AMPK and SIRT1: a long-standing partnership? Am. J. Physiol. Endocrinol. Metab. 298, E751-E760. doi: 10.1152/ajpendo.00745.2009

Sakata, T., Ferdous, G., Tsuruta, T., Satoh, T., Baba, S., Muto, T., et al. (2009). Ltype amino-acid transporter 1 as a novel biomarker for high-grade malignancy in prostate cancer. Pathol. Int. 59, 7-18. doi: 10.1111/j.1440-1827.2008.02319.x

Salisbury, T. B., and Arthur, S. (2018). The regulation and function of the Ltype amino acid transporter 1 (LAT1) in Cancer. Int. J. Mol. Sci. 19:2373. doi: $10.3390 /$ ijms 19082373
Sancak, Y., Bar-Peled, L., Zoncu, R., Markhard, A. L., Nada, S., and Sabatini, D. M. (2010). Ragulator-Rag complex targets mTORC1 to the lysosomal surface and is necessary for its activation by amino acids. Cell 141, 290-303. doi: 10.1016/j.cell.2010.02.024

Sarbassov, D. D., Ali, S. M., Kim, D. H., Guertin, D. A., Latek, R. R., ErdjumentBromage, H., et al. (2004). Rictor, a novel binding partner of mTOR, defines a rapamycin-insensitive and raptor-independent pathway that regulates the cytoskeleton. Curr. Biol. 14, 1296-1302. doi: 10.1016/j.cub.2004.06.054

Sato, K., Miyamoto, M., Takano, M., Furuya, K., and Tsuda, H. (2019). Significant relationship between the LAT1 expression pattern and chemoresistance in ovarian clear cell carcinoma. Virchows Arch. 474, 701-710. doi: 10.1007/s00428-019-02520-0

Sato, Y., Heimeier, R. A., Li, C., Deng, C., and Shi, Y. B. (2011). Extracellular domain of CD98hc is required for early murine development. Cell Biosci. 1:7. doi: 10.1186/2045-3701-1-7

Saxton, R. A., and Sabatini, D. M. (2017). mTOR signaling in growth, metabolism, and disease. Cell 169, 361-371. doi: 10.1016/j.cell.2017.03.035

Scalise, M., Galluccio, M., Console, L., Pochini, L., and Indiveri, C. (2018). The human SLC7A5 (LAT1): the intriguing histidine/large neutral amino acid transporter and its relevance to human health. Front. Chem. 6:243. doi: 10.3389/fchem.2018.00243

Shimizu, A., Kaira, K., Kato, M., Yasuda, M., Takahashi, A., Tominaga, H., et al. (2015). Prognostic significance of L-type amino acid transporter 1 (LAT1) expression in cutaneous melanoma. Melanoma Res. 25, 399-405. doi: 10.1097/CMR.0000000000000181

Sinclair, L. V., Rolf, J., Emslie, E., Shi, Y. B., Taylor, P. M., and Cantrell, D. A. (2013). Control of amino-acid transport by antigen receptors coordinates the metabolic reprogramming essential for T cell differentiation. Nat. Immunol. 14, 500-508. doi: $10.1038 /$ ni.2556

Smith, A. M., King, J. J., West, P. R., Ludwig, M. A., Donley, E. L. R., Burrier, R. E., et al. (2019). Amino acid dysregulation metabotypes: potential biomarkers for diagnosis and individualized treatment for subtypes of autism spectrum disorder. Biol. Psychiatry 85, 345-354. doi: 10.1016/j.biopsych.2018. 08.016

Tarlungeanu, D. C., Deliu, E., Dotter, C. P., Kara, M., Janiesch, P. C., Scalise, M., et al. (2016). Impaired amino acid transport at the blood brain barrier is a cause of autism spectrum disorder. Cell 167:1481-1494.e18. doi: $10.1016 /$ j.cell.2016.11.013

Taylor, P. M. (2014). Role of amino acid transporters in amino acid sensing. Am. J. Clin. Nutr. 99, 223S-230S. doi: 10.3945/ajcn.113.070086

Thiele, N. A., Karkkainen, J., Sloan, K. B., Rautio, J., and Huttunen, K. M. (2018). Secondary carbamate linker can facilitate the sustained release of dopamine from brain-targeted prodrug. Bioorg. Med. Chem. Lett. 28, 2856-2860. doi: 10.1016/j.bmcl.2018.07.030

Tomi, M., Mori, M., Tachikawa, M., Katayama, K., Terasaki, T., and Hosoya K. (2005). L-type amino acid transporter 1-mediated L-leucine transport at the inner blood-retinal barrier. Invest. Ophthalmol. Vis. Sci. 46, 2522-2530. doi: 10.1167/iovs.04-1175

Toyoda, M., Kaira, K., Ohshima, Y., Ishioka, N. S., Shino, M., Sakakura, K., et al. (2014). Prognostic significance of amino-acid transporter expression (LAT1, ASCT2, and $\mathrm{xCT}$ ) in surgically resected tongue cancer. Br. J. Cancer. 110, 2506-2513. doi: 10.1038/bjc.2014.178

Tsukada, H., Sato, K., Fukumoto, D., Nishiyama, S., Harada, N., and Kakiuchi, T. (2006). Evaluation of D-isomers of O-11C-methyl tyrosine and O$18 \mathrm{~F}$-fluoromethyl tyrosine as tumor-imaging agents in tumor-bearing mice: comparison with L- and D-11C-methionine. J. Nucl. Med. 47, 679-688.

Tsumura, H., Suzuki, N., Saito, H., Kawano, M., Otake, S., Kozuka, Y., et al. (2003). The targeted disruption of the CD98 gene results in embryonic lethality. Biochem. Biophys. Res. Commun. 308:847-851. doi: 10.1016/S0006-291X(03)01473-6

Uchino, H., Kanai, Y., Kim, D. K., Wempe, M. F., Chairoungdua, A., Morimoto, E., et al. (2002). Transport of amino acid-related compounds mediated by L-type amino acid transporter 1 (LAT1): insights into the mechanisms of substrate recognition. Mol. Pharmacol. 61, 729-737. doi: 10.1124/mol.61.4.729

Usui, T., Nagumo, Y., Watanabe, A., Kubota, T., Komatsu, K., Kobayashi, J., et al. (2006). Brasilicardin A, a natural immunosuppressant, targets amino Acid transport system L. Chem. Biol. 13, 1153-1160. doi: $10.1016 /$ j.chembiol.2006.09.006 
Venkateswaran, N., Lafita-Navarro, M. C., Hao, Y. H., Kilgore, J. A., PerezCastro, L., Braverman, J., et al. (2019). MYC promotes tryptophan uptake and metabolism by the kynurenine pathway in colon cancer. Genes Dev. 33, 1236-1251. doi: 10.1101/gad.327056.119

Verrey, F., Closs, E. I., Wagner, C. A., Palacin, M., Endou, H., and Kanai, Y. (2004). CATs and HATs: the SLC7 family of amino acid transporters. Pflugers Arch. 447, 532-542. doi: 10.1007/s00424-003-1086-z

Walderhaug, E., Lunde, H., Nordvik, J. E., Landro, N. I., Refsum, H., and Magnusson, A. (2002). Lowering of serotonin by rapid tryptophan depletion increases impulsiveness in normal individuals. Psychopharmacology 164, 385-391. doi: 10.1007/s00213-002-1238-4

Wang, Q., Bailey, C. G., Ng, C., Tiffen, J., Thoeng, A., Minhas, V., et al. (2011). Androgen receptor and nutrient signaling pathways coordinate the demand for increased amino acid transport during prostate cancer progression. Cancer Res. 71, 7525-7536. doi: 10.1158/0008-5472.CAN-11-1821

Wang, Q., Tiffen, J., Bailey, C. G., Lehman, M. L., Ritchie, W., Fazli, L., et al. (2013). Targeting amino acid transport in metastatic castration-resistant prostate cancer: effects on cell cycle, cell growth, and tumor development. J. Natl. Cancer Inst. 105, 1463-1473. doi: 10.1093/jnci/djt241

Wang, R., and Green, D. R. (2012). Metabolic checkpoints in activated T cells. Nat. Immunol. 13, 907-915. doi: 10.1038/ni.2386

Wang, Q., and Holst, J. (2015). L-type amino acid transport and cancer: targeting the mTORC1 pathway to inhibit neoplasia. Am. J. Cancer Res. 5, 1281-1294.

Xie, X. L., Kakehashi, A., Wei, M., Yamano, S., Takeshita, M., Yunoki, T., et al. (2013). L-Leucine and L-isoleucine enhance growth of BBN-induced urothelial tumors in the rat bladder by modulating expression of amino acid transporters and tumorigenesis-associated genes. Food Chem. Toxicol. 59, 137-144. doi: 10.1016/j.fct.2013.05.044

Yamamoto, Y., Sawa, R., Wake, I., Morimoto, A., and Okimura, Y. (2017). Glucosemediated inactivation of AMP-activated protein kinase reduces the levels of L-type amino acid transporter 1 mRNA in C2C12 cells. Nutr. Res. 47, 13-20. doi: 10.1016/j.nutres.2017.08.003

Yamauchi, K., Sakurai, H., Kimura, T., Wiriyasermkul, P., Nagamori, S., Kanai, Y., et al. (2009). System L amino acid transporter inhibitor enhances antitumor activity of cisplatin in a head and neck squamous cell carcinoma cell line. Cancer Lett. 276, 95-101. doi: 10.1016/j.canlet.2008.10.035

Yanagida, O., Kanai, Y., Chairoungdua, A., Kim, D. K., Segawa, H., Nii, T., et al. (2001). Human L-type amino acid transporter 1 (LAT1): characterization of function and expression in tumor cell lines. Biochim. Biophys. Acta 1514, 291-302. doi: 10.1016/S0005-2736(01)00384-4

Yanagisawa, N., Hana, K., Nakada, N., Ichinoe, M., Koizumi, W., Endou, H., et al. (2014). High expression of L-type amino acid transporter 1 as a prognostic marker in bile duct adenocarcinomas. Cancer Med. 3, 1246-1255. doi: $10.1002 /$ cam 4.272

Yanagisawa, N., Ichinoe, M., Mikami, T., Nakada, N., Hana, K., Koizumi, W., et al. (2012). High expression of L-type amino acid transporter 1 (LAT1) predicts poor prognosis in pancreatic ductal adenocarcinomas. J. Clin. Pathol. 65, 1019-1023. doi: 10.1136/jclinpath-2012-200826

Yoon, M. S. (2016). The emerging role of branched-chain amino acids in insulin resistance and metabolism. Nutrients 8:405. doi: 10.3390/nu8070405

Yothaisong, S., Namwat, N., Yongvanit, P., Khuntikeo, N., Puapairoj, A., Jutabha, P., et al. (2017). Increase in L-type amino acid transporter 1 expression during cholangiocarcinogenesis caused by liver fluke infection and its prognostic significance. Parasitol. Int. 66, 471-478. doi: 10.1016/j.parint.2015.11.011

Yu, Z., Lin, W., Rui, Z., and Jihong, P. (2018). Fibroblast-like synoviocyte migration is enhanced by IL-17-mediated overexpression of L-type amino acid transporter 1 (LAT1) via the mTOR/4E-BP1 pathway. Amino Acids 50, 331-340. doi: 10.1007/s00726-017-2520-4

Yue, M., Jiang, J., Gao, P., Liu, H., and Qing, G. (2017). Oncogenic MYC activates a feedforward regulatory loop promoting essential amino acid metabolism and tumorigenesis. Cell Rep. 21, 3819-3832. doi: 10.1016/j.celrep.2017.12.002

Yun, D. W., Lee, S. A., Park, M. G., Kim, J. S., Yu, S. K., Park, M. R., et al. (2014). JPH203, an L-type amino acid transporter 1-selective compound, induces apoptosis of YD-38 human oral cancer cells. J. Pharmacol. Sci. 124, 208-217. doi: 10.1254/jphs.13154FP

Zheng, Y., Delgoffe, G. M., Meyer, C. F., Chan, W., and Powell, J. D. (2009). Anergic $\mathrm{T}$ cells are metabolically anergic. J. Immunol. 183, 6095-6101. doi: 10.4049/jimmunol.0803510

Zoncu, R., Bar-Peled, L., Efeyan, A., Wang, S., Sancak, Y., and Sabatini, D. M. (2011). mTORC1 senses lysosomal amino acids through an inside-out mechanism that requires the vacuolar $\mathrm{H}(+)$-ATPase. Science 334, 678-683. doi: $10.1126 /$ science. 1207056

Conflict of Interest: The authors declare that the research was conducted in the absence of any commercial or financial relationships that could be construed as a potential conflict of interest.

Copyright (C) 2020 Zhang, Xu, Li, Fu, Zhang, Bao and Zheng. This is an open-access article distributed under the terms of the Creative Commons Attribution License (CC $B Y)$. The use, distribution or reproduction in other forums is permitted, provided the original author(s) and the copyright owner(s) are credited and that the original publication in this journal is cited, in accordance with accepted academic practice. No use, distribution or reproduction is permitted which does not comply with these terms. 